\title{
Prognostic precipitation with three liquid water classes in the ECHAM5-HAM GCM
}

\author{
V. Sant ${ }^{1, a}$, R. Posselt ${ }^{2}$, and U. Lohmann ${ }^{1}$ \\ ${ }^{1}$ Institute of Atmospheric and Climate Science, ETH Zürich, Zürich, Switzerland \\ ${ }^{2}$ Federal Institute for Meteorology and Climatology, MeteoSchweiz, Zürich, Switzerland \\ anow at: Max Planck Institute for Meteorology, Hamburg, Germany \\ Correspondence to: V. Sant (vivek.sant@mpimet.mpg.de)
}

Received: 9 February 2015 - Published in Atmos. Chem. Phys. Discuss.: 12 March 2015

Revised: 15 June 2015 - Accepted: 17 July 2015 - Published: 7 August 2015

\begin{abstract}
A new parameterization with three prognostic liquid water classes was implemented into the general circulation model (GCM) ECHAM5 with the aerosol module HAM in order to improve the global representation of rain formation in marine stratiform clouds. The additionally introduced drizzle class improves the physical representation of the droplet spectrum and, more importantly, improves the microphysical processes relevant for precipitation formation compared to the standard parameterization. In order to avoid a mismatch of the liquid and ice phase, a prognostic treatment of snow has been introduced too. This has a significant effect on the amount and altitude of ice clouds, which in turn affects not only the in- and outgoing radiation but also the parameterized collection rates. With the introduction of a prognostic precipitation scheme, a more realistic representation of both liquid and ice phase large-scale precipitation is achieved compared to a diagnostic treatment. An encouraging finding is that with the prognostic treatment the increase of the liquid water path in response to anthropogenic aerosols is reduced by about $25 \%$. Although the total net radiative forcing is decreased from $-1.3 \pm 0.3$ to $-1.6 \pm 0.3 \mathrm{~W} \mathrm{~m}^{-2}$ from the control to the prognostic model version, the difference is within the interannual variability. Altogether the results suggest that the treatment of precipitation in global circulation models has not only a significant influence on the phase of clouds and their conversion rates, but also hints towards uncertainties related to a prognostic precipitation scheme.
\end{abstract}

\section{Introduction}

The challenge of projecting future climate, its sensitivity to anthropogenic forcing, the change in global precipitation patterns and the mitigation of climate change remains difficult and is closely linked to correctly representing the radiative forcing. The greatest uncertainty lies in the representation of clouds (e.g., Stephens, 2005), whether it is their fundamental coupling to the large-scale circulation (Stevens and Bony, 2013) or their interaction with anthropogenic aerosols on very fine scales (Boucher et al., 2013). As resolution in general circulation models (GCMs) remains coarse $(O(100 \mathrm{~km}))$, the improvements made on subgrid-scale processes are a priori limited, whether this be for the parameterization of convection, turbulence or microphysics, as all parameterizations are governed by the resolved larger scales. Nevertheless, understanding the dependence of the subgridscale parameterizations and improving crude representations of subgrid-scale processes is crucial for climate models to hopefully reduce the error in climate projections.

One of the largest uncertainties is the response of clouds and precipitation to changes in aerosol concentrations (Stevens and Feingold, 2009). Aerosols are necessary for the formation of clouds by acting as cloud condensation nuclei (CCN) or ice nuclei (IN) and changes in the CCN and IN number concentrations affect the number of cloud droplets or ice crystals. Thin, low level marine stratus and stratocumulus are known to be very susceptible to changes in aerosol concentration. Being very widespread, they constitute a major source of uncertainty in climate models (e.g., Bony and Dufresne, 2005). Traditionally, an increase in aerosols is thought to ultimately lead to brighter (Twomey, 
1974) and maybe longer-lived clouds (Albrecht, 1989), reasoning that the increase in CCN leads to more but smaller cloud droplets, consequently reducing the efficiency to form rain. Since cloud droplets have to first collide and coalesce to form small rain or drizzle drops (autoconversion), before further collection of cloud droplets by drizzle drops (accretion) produce a significant amount of rain, an increase in cloud droplets can influence the precipitation formation. While there is ample evidence for higher $\mathrm{CCN}$ concentrations leading to more cloud droplets, the subsequent effect on the cloud amount and precipitation is highly debated. The suppression of precipitation is found to be in competition with the evaporation by entrainment of dry air (Ackerman et al., 2004; Jiang et al., 2006; Boucher et al., 2013).

Many GCMs do not have the ability to include such compensating effects on small scales. Thus, it is not surprising that for mixed- or ice phase clouds, the influence of aerosols on the radiative budget is still unclear (Boucher et al., 2013). For mixed-phase clouds an increase in aerosols can lead to two competing effects, namely, the glaciation effect and the de-activation effect (Lohmann and Hoose, 2009). With more IN, the cloud would glaciate and form precipitation more readily reducing its radiative effect. On the other hand, IN may also be coated with soluble material, i.e., sulfate, reducing its nucleation ability and having the opposite effect.

Whether it is for liquid, mixed- or ice phase clouds, describing the influence of aerosols on clouds and precipitation formation requires a whole chain of processes that need to be considered. Here the focus will be on the collection processes and the sensitivity of the model to the anthropogenic aerosol forcing.

The increase in aerosol concentrations since the preindustrial era has led to a negative radiative forcing corresponding to a cooling that partly offsets the greenhouse gas warming (Boucher et al., 2013). The radiative forcing is comprised of (i) a direct influence of the aerosols on the in- and outgoing radiation and (ii) an indirect influence of aerosols by changing cloud properties. GCMs have shown to overestimate the cooling related to these aerosol-cloudprecipitation interactions compared to observations (Quaas et al., 2009). Posselt and Lohmann (2008a) showed that the diagnostic treatment of rain in GCMs results in an overemphasis of the autoconversion process, which leads to a high sensitivity of clouds and thus formation of precipitation to changes in aerosol concentrations. By introducing a prognostic treatment of rain, a more realistic partitioning between the autoconversion and accretion process can be achieved (Posselt and Lohmann, 2008a; Gettelman and Morrison, 2015). Further studies following suit (Reitter et al., 2011; Walters et al., 2014; Gettelman et al., 2015) or using a multi-scale modeling framework (Wang et al., 2011) confirm these findings, not only reducing the sensitivity of clouds and precipitation to the anthropogenic aerosol forcing, but also improving the representation of cloud ice and snow (Reitter et al., 2011) and reducing the frequency of unrealistic light rain (Walters et al., 2014).

As a follow-on to the work by Posselt and Lohmann (2008a) and Posselt and Lohmann (2009), where the importance of the drop size distribution (DSD) in low level clouds was recognized, this study focuses on the representation of both liquid and solid phase precipitation in the ECHAM5HAM GCM and its response to the anthropogenic aerosol forcing.

For the liquid phase, an intermediate drizzle drop class is introduced following the triclass parameterization by Sant et al. (2013) for the collection processes, i.e., autoconversion, accretion and self-collection, of the three liquid water classes. Although the idea of a three class system to capture the broadening of the DSD is older (Lüpkes et al., 1989), the concept was picked up to enable applications that benefit from an explicit drizzle class. In particular, to improve the influence of different $\mathrm{CCN}$ and giant $\mathrm{CCN}$ on the formation of drizzle drops (e.g., Saleeby and Cotton, 2004; Posselt and Lohmann, 2008b) or their effect on the cloud-top effective radius (Wood, 2000). However, first and foremost the scheme allows for a more physical representation of the DSD, since it is based on truncated moments, and consequently the collection rates. This enables one to better capture the drizzling conditions often found in marine stratocumulus (van Zanten et al., 2005). Furthermore, the triclass scheme helps represent the transition from low to larger precipitation rates and improves the sensitivity of surface precipitation to changes in $\mathrm{CCN}$ compared to the standard scheme used in the ECHAM5-HAM GCM (Sant et al., 2013). Therefore, here the focus will be on the triclass scheme and the prognostic precipitation as a whole, leaving the application of giant $\mathrm{CCN}$ and the estimation of the cloud-top effective radius for the future.

A weakness of the previous studies was the biased improvement of only the liquid phase, i.e., the treatment of snow remained diagnostic. Consequently, similar to the work done by Gettelman and Morrison (2015) and Gettelman et al. (2015) in the CAM5 model, a full prognostic treatment of precipitation is introduced for drizzle, rain and snow.

The outline of the article is as follows. Section 2 will give a general description of the ECHAM5-HAM GCM and the changes made by introducing the prognostic treatment of precipitation. Results are presented in Sect. 3 starting with global fields before looking at the cloud properties and the precipitation microphysics. The section ends with the comparison of present-day (PD) and pre-industrial (PI) simulations. Finally, the conclusions are presented in Sect. 4. 


\section{Model description}

\subsection{ECHAM5-HAM GCM}

For this study, the ECHAM5-HAM GCM (Roeckner et al., 2003) coupled to the two-moment modal aerosol scheme HAM (Stier et al., 2005) is used as in Lohmann and Hoose (2009). The model solves the prognostic equations for temperature, surface pressure, divergence and vorticity on a spectral grid with a triangular truncation. Within HAM the aerosol size distribution is represented by a superposition of seven lognormal distributions describing the different sizes and solubilities for the compounds sulfate, black carbon, organic carbon, sea salt and mineral dust.

This ECHAM5 control version (CTRL) includes a twomoment stratiform cloud microphysics scheme for cloud droplets and ice crystals (Lohmann et al., 2007) coupled to the aerosol scheme HAM, and uses an empirical cloud cover scheme (Sundqvist et al., 1989). The microphysics scheme includes all phase changes between the water components (vapor, liquid and ice), the collection processes (autoconversion, accretion and aggregation), evaporation of rain, melting of snow and sedimentation of cloud ice (Lohmann et al., 2007). The activation of cloud drops follows the empirical activation scheme by Lin and Leaitch (1997), which depends on the aerosol number concentration and the subgrid-scale updraft velocity. Cirrus clouds form by homogeneous freezing of supercooled solution drops (Lohmann et al., 2008), which has been found to be the dominant freezing mechanism for these types of clouds (Kärcher and Ström, 2003); however, recently this view has been questioned (Cziczo et al., 2013).

The CTRL version of the model treats precipitation diagnostically (Ghan and Easter, 1992); i.e., it reaches the surface within one model time step or evaporates/sublimates in the sub-saturated air below the cloud. Following Khairoutdinov and Kogan (2000) for the collection processes, cloud and rain water are separated at a radius of $25 \mu \mathrm{m}$. However, the diagnostic treatment of rain is only realistic for drops larger than $100 \mu \mathrm{m}$, which lead Posselt and Lohmann (2008a) to the introduction of a prognostic rain scheme to account for the drizzling conditions often found in marine stratocumulus. Yet, one is still left with the rain class spanning all drops larger than $25 \mu \mathrm{m}$ in radius, which tends to overestimate the number concentration of large drops and thus influences both the collection processes and the sedimentation. Consequently, we introduce drizzle $(25<r<100 \mu \mathrm{m})$ as a third liquid water class and implement the triclass parameterization by Sant et al. (2013) to describe the collection processes based on truncated moments. In this model version, which is referred to as PROG, prognostic equations for both liquid and ice phase precipitation are introduced for both mass and number for consistency. Note that, for both model versions only the cloud liquid and ice water contribute to the cloud optical properties; i.e., no changes have been made to the ra-

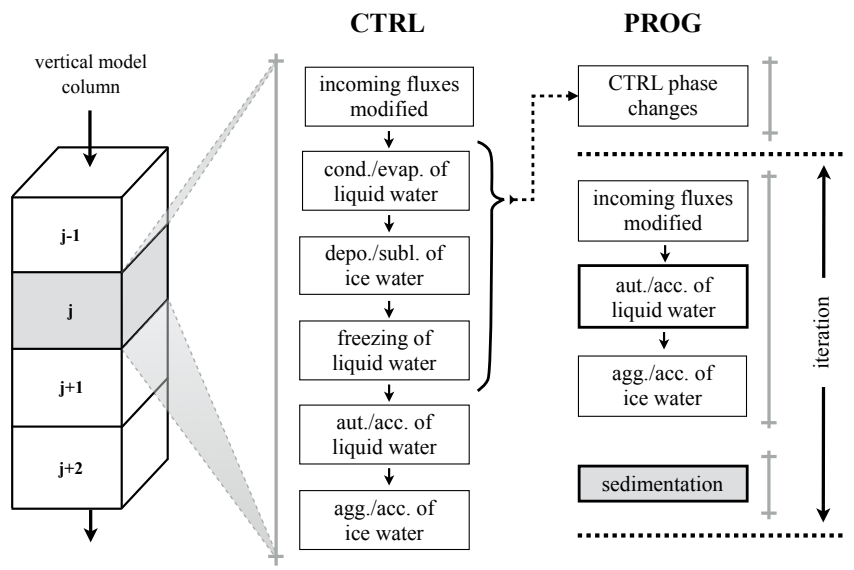

Figure 1. Schematic flowchart of the CTRL and PROG microphysics schemes. The gray vertical bars denote vertical loops (illustrated by the vertical model column on the left), the boxes in bold are new or changed schemes, and the sedimentation can be subject to a further time splitting if necessary.

diation scheme. Adding the prognostic precipitation hydrometeors (drizzle, rain and snow) into the radiation scheme will be part of future work.

With the introduction of the new collection scheme for the three liquid water classes and the prognostic precipitation scheme, the climate model is not necessarily in radiative equilibrium anymore as the parameter space for the tuning has changed (Lohmann and Ferrachat, 2010). To preserve comparability of the two model versions the tuning parameters were not changed. Yet, if the climate impacts for both liquid and ice phase microphysics between CTRL and PROG are comparable in terms of heating rates (Mauritsen et al., 2012), a similar climate can be expected.

\subsection{Prognostic precipitation}

For the prognostic precipitation scheme, the microphysical processes had to be restructured as illustrated by the flowchart in Fig. 1. In CTRL the microphysical processes are treated sequentially: first, the incoming precipitation fluxes (rain and snow) from the level above are modified by melting, sublimation and evaporation. This is followed by microphysical processes on cloud water and ice, i.e., condensation or evaporation, deposition or sublimation and freezing of cloud water. These processes do not interact with the precipitating water and, for simplicity, will be referred to as the "phase changes". Then the conversion of cloud water (ice) to rain (snow) via autoconversion (aggregation) and the interaction of the two via accretion is calculated. The fluxes and tendencies of the given grid box are finally updated and the whole procedure is repeated for the next level down until reaching the surface.

For PROG the vertical loop is split into three loops: the first one computes the "phase changes", the second the for- 
mation of precipitation and its interaction with the cloud water and ice, and the third the sedimentation. The latter two are then subject to a sub-stepping over smaller time steps, i.e., time splitting. Primarily, this is done to assure numerical stability of the sedimentation, as the Courant-Friedrichs-Lewy (CFL) criterion needs to be met, and to improve the representation of the microphysical processes. Note that the sedimentation itself can be made subject to an additional time splitting if necessary. Since the whole model could not be subjected to smaller time steps, the time splitting is only applied to processes relevant to the formation and sedimentation of precipitation. Furthermore, the splitting of the vertical loop is necessary as some cloud processes use a moisture adjustment scheme, which is not time dependent and would lead to inconsistencies if included in the time splitting. The number of iterations needed for the time splitting, i.e., the length of the sub-time step, depends on the fall speeds and the new triclass parameterization. Tests in single column mode showed that a sub-time step of $30 \mathrm{~s}$ leads to a good convergence in surface precipitation and conversion rates, keeping the computational costs at a reasonable level (Sant, 2012).

The microphysical rates for drizzle (d), rain (r) and snow (s) mass mixing ratio, $\partial q_{i} / \partial t, i \in\{\mathrm{d}, \mathrm{r}, \mathrm{s}\}$, and number concentration, $\partial N_{i} / \partial t$, can be summarized as follows:

$$
\begin{aligned}
& \frac{\partial q_{\mathrm{d}}}{\partial t}=b_{\mathrm{c}}\left(Q_{\mathrm{aut}_{\mathrm{c}}}-Q_{\mathrm{aut}_{\mathrm{d}}}+Q_{\mathrm{ac}_{\mathrm{cd}-}}-Q_{\mathrm{ac}_{\mathrm{cd}-}}-Q_{\mathrm{ac}_{\mathrm{dr}}}\right) \\
& -\left(1-b_{\mathrm{c}}\right) Q_{\mathrm{evp}_{\mathrm{d}}}+b_{\mathrm{r}} Q_{\mathrm{sed}_{\mathrm{d}}}, \\
& \frac{\partial N_{\mathrm{d}}}{\partial t}=b_{\mathrm{c}}\left(P_{\mathrm{aut}_{\mathrm{c}}}-P_{\mathrm{aut}_{\mathrm{d}}}-P_{\mathrm{ac}_{\mathrm{cd}-}}-P_{\mathrm{sc}_{\mathrm{d}}}\right) \\
& -\left(1-b_{\mathrm{c}}\right) P_{\mathrm{evp}_{\mathrm{d}}}+b_{\mathrm{r}} P_{\mathrm{sed}_{\mathrm{d}}}, \\
& \frac{\partial q_{\mathrm{r}}}{\partial t}=b_{\mathrm{c}}\left(Q_{\mathrm{aut}_{\mathrm{d}}}+Q_{\mathrm{ac}_{\mathrm{cr}}}+Q_{\mathrm{ac}_{\mathrm{cd}-}}+Q_{\mathrm{ac}_{\mathrm{dr}}}\right) \\
& -\left(1-b_{\mathrm{c}}\right) Q_{\mathrm{evp}_{\mathrm{r}}}+b_{\mathrm{r}}\left(Q_{\mathrm{mlt}_{\mathrm{t}}}+Q_{\mathrm{sed}_{\mathrm{r}}}\right), \\
& \frac{\partial N_{\mathrm{r}}}{\partial t}=b_{\mathrm{c}}\left(P_{\mathrm{aut}_{\mathrm{d}}}+P_{\mathrm{ac}_{\mathrm{cd}-}}-P_{\mathrm{sc}_{\mathrm{r}}}\right)-\left(1-b_{\mathrm{c}}\right) \\
& P_{\mathrm{evp}_{\mathrm{r}}}+b_{\mathrm{r}}\left(P_{\mathrm{mlt}_{\mathrm{t}}}+P_{\mathrm{sed}_{\mathrm{r}}}\right), \\
& \frac{\partial q_{\mathrm{s}}}{\partial t}=b_{\mathrm{c}}\left(Q_{\mathrm{agg}}+Q_{\mathrm{ac}_{\mathrm{s}}}\right)-\left(1-b_{\mathrm{c}}\right) Q_{\mathrm{sub}} \\
& +b_{\mathrm{r}}\left(-Q_{\mathrm{mlt}}-Q_{\mathrm{sec}}+Q_{\mathrm{sed}_{\mathrm{s}}}\right), \\
& \frac{\partial N_{\mathrm{s}}}{\partial t}=b_{\mathrm{c}} P_{\mathrm{agg}}+b_{\mathrm{r}}\left(-P_{\mathrm{mlt}_{\mathrm{ta}}}-P_{\mathrm{sec}}+P_{\mathrm{sed}_{\mathrm{s}}}\right),
\end{aligned}
$$

where $Q_{(.)}$and $P_{(.)}$account for changes in mass and number, respectively, and the cloud and total precipitation fraction are denoted by $b_{\mathrm{c}}$ and $b_{\mathrm{r}}$, respectively. Note that $b_{\mathrm{r}}$ represents the total fraction of precipitating drizzle, rain and snow and is calculated as in CTRL, where at a given level it is weighted by the incoming and locally produced mass flux or defined as $b_{\mathrm{r}}=b_{\mathrm{c}}$ if the locally produced precipitation exceeds the incoming flux (Roeckner et al., 2003, chap. 10.3.6). The source and sink terms related to the triclass parameterization for the collection processes are given in Sant et al. (2013) with some adjustments discussed later. For clarity all acronyms are summarized in Table 1.

For the ice microphysical processes the same parameterizations used in CTRL are also used in PROG. Due to the diagnostic treatment of precipitation in CTRL, the number concentrations of the precipitating hydrometeors are not needed. In PROG they are indispensable and underlie certain assumptions. During the evaporation of drizzle and rain drops a constant mean mass is assumed, hence the change in mass is followed by an associated equal fractional change in number density. As pointed out by Seifert (2008), this assumption holds rather well for drizzling stratocumulus (e.g., Khairoutdinov and Kogan, 2000). Following the formulation by Levkov et al. (1992) for the production of snow as described in Lohmann and Roeckner (1996), the snow mass created by aggregation was assumed to have a minimum diameter of $200 \mu \mathrm{m}$. This assumption together with the mass-length relation by Spichtinger and Gierens (2009) was used to determine the snow flake number concentration. When snow crystals melt they are assumed to be a source term for the rain drops, where one snow crystal is assumed to produce one rain drop. Note that the gain of snow mass due to accretion is assumed not to change the number of snow crystals.

It should be mentioned, that while the separation of the liquid water into distinct classes (cloud, drizzle and rain water) is mainly based on the accretion process leading to a minimum in the mass density distribution between cloud and drizzle drops, the separation of the ice phase into cloud ice and snow is not as clear (Morrison and Grabowski, 2008). More specifically, this is due to the importance of diffusional growth of ice crystals leading to a gradual growth and making the distinction less clear. Morrison and Grabowski (2008) presented a framework in which the number of ice water classes is reduced to a single one, retaining the history of rimed mass and allowing for a more physical representation of the growth of the ice particles. Recent progress has been made improving the scheme (Morrison and Milbrandt, 2015) and implementing it into a higher resolved regional model (Morrison et al., 2015), but it remains to be tested in a GCM.

\subsubsection{Sedimentation}

Following Posselt and Lohmann (2008a, 2009) and Müller (2007), the sedimentation of all three precipitating hydrometeor types, $i(\in\{d, r, s\})$, is treated as a vertical 1-D advection with the mass and number weighted fall velocities, $v_{q_{i}}$ and $v_{N_{i}}$, for the mass and number density, $q_{i}$ and $N_{i}$, respectively, allowing for gravitational sorting. Numerically an explicit Euler scheme was used, which by definition conserves mass. As described in Posselt and Lohmann (2008a) the sedimentation velocities are derived by using the flux density approach by Srivastava (1978, Eqs. 48 and 49) for both mass 
Table 1. Description of the different acronyms used in Eqs. (1)-(6) to describe the sinks and sources of the different hydrometeors.

\begin{tabular}{ll}
\hline Acronym & Description \\
\hline $\mathrm{aut}_{\mathrm{c}}, \mathrm{aut}_{\mathrm{d}}$ & Autoconversion of cloud droplets and drizzle drops, respectively. \\
$\mathrm{ac}_{\mathrm{cd}+}, \mathrm{ac}_{\mathrm{cd}-}$ & Source and sink of the accretion of cloud droplets by drizzle drops, respectively. \\
$\mathrm{ac}_{\mathrm{cr}}, \mathrm{ac}_{\mathrm{dr}}$ & Accretion of cloud droplets and drizzle drops by rain drops, respectively. \\
$\mathrm{sc}_{\mathrm{d}}, \mathrm{sc}_{\mathrm{r}}$ & Self-collection for drizzle and rain drops, respectively. \\
$\mathrm{agg}, \mathrm{ac}_{\mathrm{s}}$ & Aggregation of ice crystals to form snow and accretion of ice crystals and cloud droplets by snow. \\
$\mathrm{sec}$ & Secondary production of ice crystals by splintering of snow flakes. \\
$\mathrm{evp}_{\mathrm{d}}, \mathrm{evp}_{\mathrm{r}}$ & Evaporation for drizzle and rain drops, respectively. \\
$\mathrm{sub}_{\mathrm{mlt}}$ & Sublimation and melting of snow, respectively. \\
$\operatorname{sed}_{\mathrm{d}}, \mathrm{sed}_{\mathrm{r}}, \mathrm{sed}_{\mathrm{s}}$ & Sedimentation of drizzle, rain and snow, respectively. \\
\hline
\end{tabular}

and number, respectively,

$\mathfrak{F}_{q_{i}}=q_{i} v_{q_{i}}=\frac{\pi}{6} \rho_{\mathrm{w}} \int_{0}^{\infty} D^{3} f_{i}(D) v_{\mathrm{t}, i}(D) \mathrm{d} D$,

$\mathfrak{F}_{N_{i}}=N_{i} v_{N_{i}}=\int_{0}^{\infty} f_{i}(D) v_{\mathrm{t}, i}(D) \mathrm{d} D$,

where $\rho_{\mathrm{w}}$ is the density of water and $v_{\mathrm{t}, i}$ is the terminal velocity of the corresponding hydrometeor with diameter $D$. Note that with this approach, changes in mass density with height, due to changes in air density, are taken into account. Following Posselt and Lohmann (2009), the number density function $f_{i}$ is assumed to follow a gamma distribution of the following form:

$f_{i}(D)=\frac{N_{i}}{\Gamma\left(\mu_{i}\right) D}\left(\frac{D}{D_{0, i}}\right)^{\mu_{i}} \exp \left(-\frac{D}{D_{0, i}}\right)$

where $\Gamma$ (.) is the gamma function, $\mu_{i}$ is a free shape parameter and $D_{0, i}$ is related to the mean diameter $\bar{D}_{i}$ by

$D_{0, i}=\frac{\bar{D}_{i}}{\sqrt[3]{\mu_{i}\left(\mu_{i}+1\right)\left(\mu_{i}+2\right)}}$

with

$\bar{D}_{i}=\sqrt[3]{\frac{6}{\pi \rho_{\mathrm{w}}} \frac{\rho_{a} q_{i}}{N_{i}}}$.

By determining the terminal velocity $v_{\mathrm{t}, i}(D)$ of a single drop or crystal, Eqs. (7) and (8) can be solved for the bulk fall velocities, $v_{q_{i}}$ and $v_{N_{i}}$.

For the liquid phase, i.e., drizzle and rain drops, the terminal velocity of a single drop was determined using an approximated expression based on Rogers et al. (1993). Integrating Eqs. (7) and (8) yields the bulk fall velocities (cf. Posselt and
Lohmann, 2009)

$$
\begin{aligned}
& v_{q_{i}}=\left\{\begin{array}{ll}
\left(\mu_{i}+3\right) b_{v} D_{0, i}, & \text { for } D_{0, i} \leq D_{v} /\left(\mu_{i}+3\right) \\
b_{1}, & \text { for } D_{0, i}>D_{v} /\left(\mu_{i}+3\right)
\end{array},\right. \\
& v_{N_{i}}= \begin{cases}\mu_{i} b_{v} D_{0, i}, & \text { for } D_{0, i} \leq D_{v} / \mu_{i} \\
b_{1}, & \text { for } D_{0, i}>D_{v} / \mu_{i}\end{cases}
\end{aligned}
$$

where the constant $b_{v}=b_{3}\left(b_{2}-5\left(b_{2}-b_{1}\right)\right)=3918 \mathrm{~s}^{-1}$ and the critical distribution parameter $D_{v}$ is given by $D_{v}=$ $b_{1} / b_{v}=2463 \mu \mathrm{m}$. Equations (12) and (13) are used for both drizzle and rain drops, where the shape parameters $\mu_{\mathrm{d}}$ and $\mu_{\mathrm{r}}$ were chosen assuming a constant value of $\mu_{\mathrm{d}}=\mu_{\mathrm{r}}=5$. This choice follows the findings by Posselt and Lohmann (2009) and results in a distribution width, which is not too wide as to not overestimate the number of large drops, but wide enough to enable gravitational sorting. A direct link to the assumed distributions for the collection processes cannot be made, as sedimentation is based on grid mean values whereas the collection rates are based on in-cloud values. This incoherence should be avoided in future climate models. Note that for large $D_{0, i}$ or $\mu_{i}$, gravitational sorting does not occur anymore as $v_{q_{i}}$ and $v_{N_{i}}$ converge. In this case $\bar{D}_{i}$ would have to be approximately $2 \mathrm{~mm}$ or larger, a regime not found in our simulations.

For snow flakes the terminal fall velocity of a single snow crystal is determined following Barthazy and Schefold (2006):

$v_{\mathrm{t}, i}(D)=\beta_{1} D^{\beta_{2}}$,

assuming irregular crystals with $\beta_{1}=1.23$ and $\beta_{2}=0.22$, where the diameter was again determined using the masslength relation by Spichtinger and Gierens (2009). Repeating the procedure as for the liquid phase, assuming the same number distribution, $f_{i}(D)$ yields the following bulk fall ve- 
locities for snow

$v_{q_{\mathrm{s}}}=\beta_{1} D_{0, i}^{3+\beta_{2}} \frac{\Gamma\left(3+\mu_{\mathrm{s}}+\beta_{2}\right)}{\Gamma\left(3+\mu_{\mathrm{s}}\right)}$,

$v_{N_{\mathrm{s}}}=\beta_{1} D_{0, i}^{\beta_{2}} \frac{\Gamma\left(\mu_{\mathrm{s}}+\beta_{2}\right)}{\Gamma\left(\mu_{\mathrm{s}}\right)}$.

For consistency with Levkov et al. (1992), it is assumed that the size distribution of snow follows an exponential distribution; i.e., $\mu_{\mathrm{s}}=1$ with respect to Eq. (9).

\subsubsection{Collection processes}

In CTRL the collection processes responsible for the formation of precipitation follow the formulation by Khairoutdinov and Kogan (2000). With the introduction of drizzle as a third liquid water class in PROG, the collection processes of autoconversion, accretion and self-collection are reformulated using the scheme by Sant et al. (2013). By solving the stochastic collection equation for truncated moments, twomoment rate equations are derived for cloud, drizzle and rain mass and number densities. However, as the scheme is computationally rather expensive, especially for the numerical solution of contained integrals, an approximation is presented here. The integrals in question (cf. Sant et al., 2013, Appendix B) are normalized by the number concentration and then approximated by a polynomial in log-space with a nonlinear least square fit using a Levenberg-Marquardt algorithm (Press et al., 1992). The details of the approximation are presented in the Appendix.

This approximation introduces a small error, mainly due to the integral used for the accretion between cloud and drizzle drops, as the dependence on the shape parameters and the continuity condition are larger than for the other approximated integrals (cf. Sant et al., 2013). Tests have shown that the error is within a few percent of the produced precipitation. This is very reasonable, especially in view of reduced computational cost. The approximation reduces the computational costs of the model calculation (whole atmosphere) by about a factor of 2.5 , leaving the calculation of PROG to be a factor of 2.5 - instead of 6 - higher than CTRL. These numbers are based on a time step of $30 \mathrm{~s}$ for the time splitting.

\section{Results}

\subsection{Model setup}

All global simulations presented here are conducted at a horizontal resolution of $\mathrm{T} 63\left(\sim 1.875^{\circ} \times 1.875^{\circ}\right)$ with 31 vertical levels, where the uppermost level interface is at $10 \mathrm{hPa}$. For PROG the model time step of $12 \mathrm{~min}$ is divided into 24 subtime steps for all precipitation processes as described above, such that a time step of $30 \mathrm{~s}$ is reached for the time splitting. Using climatological sea surface temperatures (SSTs) and sea ice extent, the simulations are integrated for 12 years (2000-2011) after a spin-up of 3 months. For a closer look at in-cloud processes, further statistics were made based on 6-hourly data of the year 2000. This proved to be sufficient to get a good sampling of the parameter space.

To estimate the total anthropogenic aerosol effect, which is the change of the net radiation at the top of the atmosphere (TOA) due to anthropogenic aerosols, simulations with PD and PI aerosol emissions integrated over the same 12 years are compared. The PI simulations use natural aerosol emissions representative of the year 1750 (Dentener et al., 2006).

\subsection{Present-day results}

\subsubsection{Global and zonal fields}

The global and zonal annual mean cloud properties and TOA energy budget are presented in Table 2 and Fig. 2, respectively, for the simulations with PROG and CTRL, together with observations for comparison. The total precipitation amount is very similar in both PROG and CTRL, both overestimating the observed amount from the Global Precipitation Climatology Project (GPCP) data set of the years 19792001 (Adler et al., 2003). The overestimation is mainly located in the tropics and subtropics as can be seen in Fig. 2 a. Separating the total precipitation into stratiform, i.e., large scale, and convective precipitation, a shift to more stratiform precipitation in PROG can be deduced, while at the same time reducing the amount of convective precipitation. Although the differences in the zonal mean are not very pronounced (cf. Fig. 2b and d), the largest difference between PROG and CTRL is seen in stratiform precipitation in the tropics. In addition, the fraction of stratiform precipitation falling as snow is shown in Fig. 2c, where a slight shift towards the tropics is seen in PROG. In general, the prognostic treatment of both warm and cold precipitation (drizzle, rain and snow) has little effect on the precipitation amount reaching the surface, which is to be expected as we are using climatological SSTs. Since the SSTs determine the evaporation rates over the ocean and precipitation is balanced by the amount of evaporation, the differences in precipitation amount need to be small. Nevertheless, the hydrological cycle could be altered by increasing or decreasing the cloud lifetimes through the microphysical collection processes, which will be addressed later.

The simulated total cloud cover (TCC) is within the range of observations in the zonal mean for both PROG and CTRL, differing by about one percent in the global mean between the two simulations. The differences are located in the northern midlatitudes as can be seen in Fig. 2e. Although small, they remain persistent throughout the whole simulation period.

The prognostic treatment of precipitation has a large effect on both liquid and ice water paths globally and on the zonal mean (cf. Fig. 2f-h). In a global mean, the cloud liquid wa- 

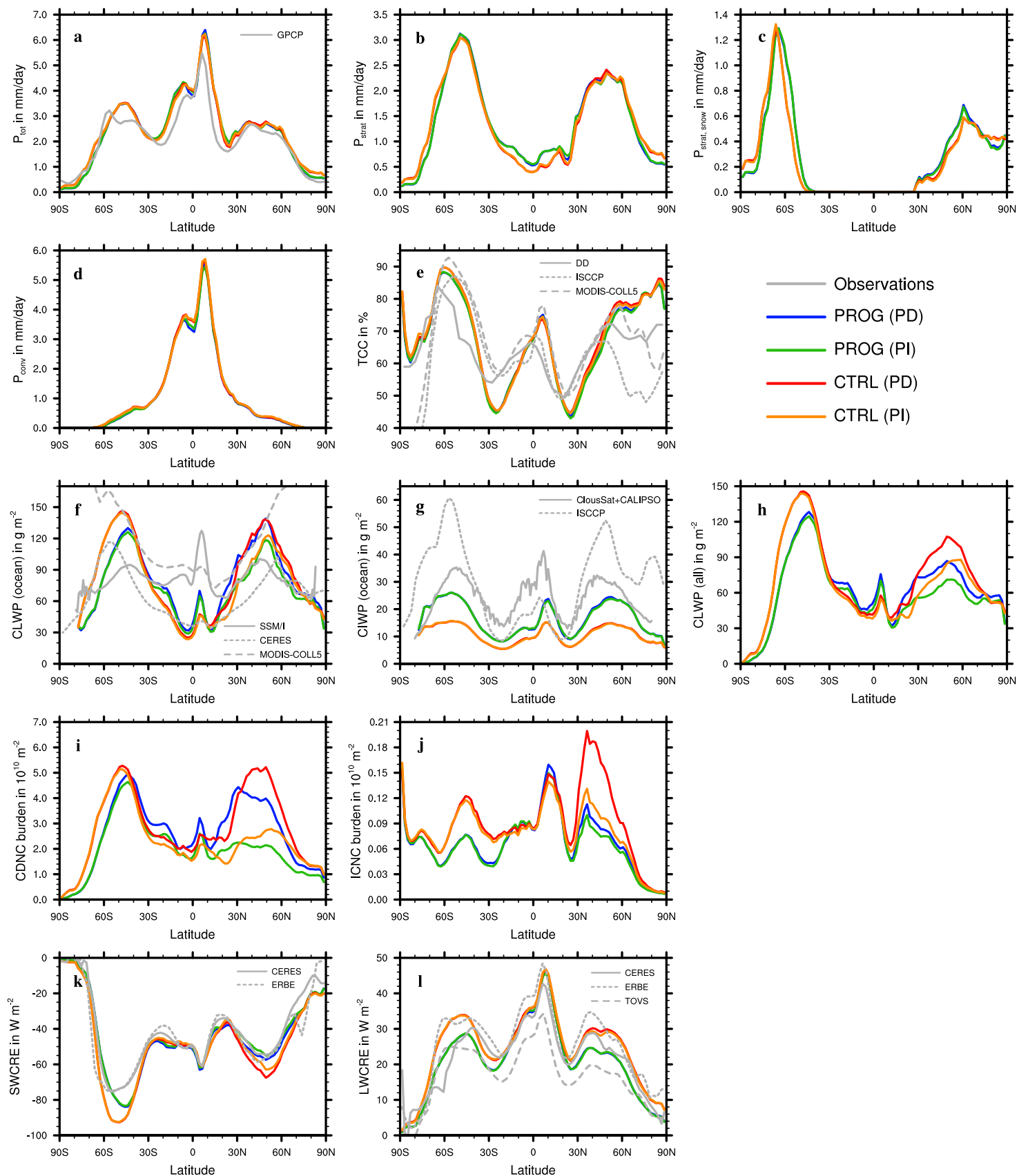

Figure 2. Zonal annual mean average of (a) total precipitation $\left(P_{\text {tot }}\right)$, (b) stratiform precipitation $\left(P_{\text {strat }}\right)$, $(\mathbf{c})$ stratiform snow precipitation $\left(P_{\text {strat, snow }}\right),(\mathbf{d})$ convective precipitation $\left(P_{\text {conv }}\right),($ e) total cloud cover (TCC), (f) cloud liquid water (CLWP) and (g) cloud ice water path (CIWP) over the ocean, (h) the CLWP over whole globe, (i) the CDNC and (j) ICNC burden, (k) shortwave (SWCRE) and (l) long-wave cloud radiative forcing (LWCRE) for PROG and CTRL (PD and PI) from 2000-2011. The following observations are used: GPCP, the Global Precipitation Climatology Project (Adler et al., 2003) in (a); DD, surface observations (Hahn et al., 1994) in (e); ISCCP, International Satellite Cloud Climatology Project (Han et al., 1998; Rossow and Schiffer, 1999) in (e, g); MODIS-COLL5, Moderate Resolution Imaging Spectroradiometer, Collection 5 (http://modis-atmos.gsfc.nasa.gov/products.html) in (e, f); SSM/I, Special Sensor Microwave/Imager (Wentz, 1997) in (f); CERES, Clouds and Earth's Radiant Energy System (Wielicki et al., 1996) in (f), (k) and (l); CloudSat + CALIPSO, ensemble mean satellite observations of CloudSat and the Cloud-Aerosol Lidar and Infrared Pathfinder Satellite Observations (Li et al., 2012) in (g); ERBE, Earth Radiation Budget Experiment (http://science.larc.nasa.gov/erbe); and TOVS (TIROS Operational Vertical Sounder) (Scott et al., 1999). 
Table 2. Global annual mean cloud properties and TOA energy budget for the simulations performed with ECHAM5-CTRL and ECHAM5PROG (2000-2011) as well as observations. Also shown are the water vapor mass (WVM) and for ECHAM5-PROG the drizzle, rain and snow water path (DWP, RWP and SWP, respectively).

\begin{tabular}{llrrrrr}
\hline & & PROG (PD) & PROG (PI) & CTRL (PD) & CTRL (PI) & Obs \\
\hline$P_{\text {tot }}$ & $\left(\mathrm{mm} \mathrm{d}^{-1}\right)$ & 2.95 & 2.96 & 2.94 & 2.95 & $2.61^{\mathrm{a}}$ \\
$P_{\text {strat }}$ & $\left(\mathrm{mm} \mathrm{d}^{-1}\right)$ & 1.42 & 1.42 & 1.35 & 1.36 & - \\
$P_{\text {conv }}$ & $\left(\mathrm{mm} \mathrm{d}^{-1}\right)$ & 1.53 & 1.54 & 1.59 & 1.60 & - \\
TCC & $(\%)$ & 63.5 & 63.2 & 64.3 & 64.1 & $65-75^{\mathrm{b}}$ \\
CLWP & $\left(\mathrm{g} \mathrm{m}^{-2}\right)$ & 69.1 & 62.5 & 74.2 & 67.5 & $50-81^{\mathrm{c}}$ \\
DWP & $\left(\mathrm{g} \mathrm{m}^{-2}\right)$ & 2.3 & 2.7 & - & - & - \\
RWP & $\left(\mathrm{g} \mathrm{m}^{-2}\right)$ & 30.7 & 30.9 & - & - & - \\
CIWP & $\left(\mathrm{g} \mathrm{m}^{-2}\right)$ & 16.2 & 16.1 & 10.6 & 10.5 & $10-65^{\mathrm{d}}$ \\
SWP & $\left(\mathrm{g} \mathrm{m}^{-2}\right)$ & 2.0 & 2.0 & - & - & - \\
WVM & $\left(\mathrm{kg} \mathrm{m}^{-2}\right)$ & 26.3 & 26.3 & 26.3 & 26.4 & $25.4^{\mathrm{e}}$ \\
CDNC burden & $\left(10^{10} \mathrm{~m}^{-2}\right)$ & 3.0 & 2.3 & 3.1 & 2.4 & - \\
ICNC burden & $\left(10^{12} \mathrm{~m}^{-2}\right)$ & 7.7 & 7.4 & 10.1 & 8.7 & - \\
AOD & $(-)$ & 0.12 & 0.09 & 0.14 & 0.11 & $0.18^{\mathrm{f}}$ \\
SW & $\left(\mathrm{W} \mathrm{m}^{-2}\right)$ & 235.0 & 236.8 & 231.8 & 233.3 & $240-244^{\mathrm{g}}$ \\
SWCRE & $\left(\mathrm{W} \mathrm{m}^{-2}\right)$ & -50.9 & -49.7 & -53.7 & -52.6 & -46 to $^{\mathrm{g}}-53^{\mathrm{h}}$ \\
LW & $\left(\mathrm{W} \mathrm{m}^{-2}\right)$ & -235.6 & -235.7 & -232.1 & -232.3 & $-(236-242)^{\mathrm{g}}$ \\
LWCRE & $\left(\mathrm{W} \mathrm{m}^{-2}\right)$ & 25.2 & 25.2 & 28.4 & 28.3 & $27-31^{\mathrm{h}}$ \\
$F_{\text {net }}$ & $\left(\mathrm{W} \mathrm{m}^{-2}\right)$ & -0.57 & 1.06 & -0.31 & 1.03 & - \\
\hline
\end{tabular}

\footnotetext{
a Precipitation rate taken from the Global Precipitation Climatology Project (GPCP) for the years 1981-2010, provided by the National Oceanic and Atmospheric Administration's Offices for Oceanic and Atmospheric Research and Earth System Reasearch Laboratory, Physical Science Division, Boulder, Colorado, USA (Adler et al., 2003) (http://www.esrl.noaa.gov/psd/). ${ }^{b}$ Total cloud cover taken from ISCCP (Rossow and Schiffer, 1999), surface observations (Hahn et al., 1994), MODIS-COLL5

(http://modis-atmos.gsfc.nasa.gov/products.html), and High Resolution Infrared Radiometer Sounder (HIRS) (Wylie et al., 2005). ${ }^{\mathrm{c}}$ Liquid water path taken from SSM/I (Greenwald et al., 1993; Weng and Grody, 1994; Wentz, 1997, only for oceans) and ISCCP (Han et al., 1998)

${ }^{d}$ Ice water path taken from Fig. 18 of Waliser et al. (2009). ${ }^{e}$ Precipitable water taken from the NASA Water Vapor Project-MEaSUREs (NVAP-M) data set as given in Vonder Haar et al. (2012). ${ }^{\mathrm{f}}$ AOD taken from Table 2 of Bellouin et al. (2013). ${ }^{\mathrm{g}}$ SW and LW taken from Fig. 1 of Wild et al. (2013). ${ }^{\text {h }}$ SWCRE and LWCRE taken from Table 4 of Loeb et al. (2009).
}

ter path (CLWP) is $7 \%$ smaller in PROG (69.1 compared to $74.2 \mathrm{~g} \mathrm{~m}^{2}$ in CTRL), where both are within the range of observations. Over the oceans, PROG exhibits a smaller CLWP in the Southern Hemisphere, but a higher peak in the tropics compared to CTRL (cf. Fig. $2 f$ and g). Over the northern hemispheric oceans the differences between the two simulations are negligible; however, taking the land into consideration (cf. Fig. 2h) reveals that the reduction in CLWP is located in the midlatitudes of both hemispheres, where stratiform clouds are dominant. On the other hand, the cloud ice water path (CIWP) is nearly $60 \%$ larger in PROG and although still strongly underestimating the observations, it can be seen as an improvement. Summed up (CLWP + CIWP, not shown) the CLWP dominates the zonal mean, where PROG shows a reduced water path in the midlatitudes but a larger peak in the tropics. In general, the peaks in both CLWP and CIWP in the tropics are in better agreement with observations.

The prognostic scheme also has a significant impact on the vertically integrated cloud droplet number concentration (CDNC burden) and the ice crystal number concentration (ICNC burden). Even though the global mean CDNC burden has hardly changed ( $3 \%$ reduction) from CTRL to PROG, the effect is more prominent on a zonal mean, where differences are seen in the midlatitudes (cf. Fig. 2i). For the ICNC burden the prognostic scheme has lead to a $25 \%$ reduction, again located in the midlatitudes but especially large in the Northern Hemisphere (cf. Fig. 2j). The reason for these effects and the relation to the water paths will be discussed in more detail below.

The link between the cloud properties and the TOA radiative effects is a little more intricate. The reduced CLWP and cloud lifetime in PROG compared to CTRL has increased the shortwave cloud radiative effect (SWCRE; notation used as in Boucher et al., 2013) by nearly $3 \mathrm{~W} \mathrm{~m}^{-2}$ in the global mean, which means that less shortwave radiation is reflected back to space. In the zonal mean shown in Fig. $2 \mathrm{k}$, this increase can be found again in midlatitudes corresponding to the location of the largest changes in CLWP. The long-wave cloud radiative effect (LWCRE) tends to be more sensitive to the TCC. As the reduction in TCC is not very large, it cannot account for the reduction of $3 \mathrm{~W} \mathrm{~m}^{-2}$ in LWCRE from CTRL to PROG. As the increase in CIWP is accompanied by a decrease in ICNC burden in PROG, the ice crystals are larger, causing a reduction in the optical depth of ice clouds. 
The reduction of TCC and in ice clouds optical depth are the reason for the reduction in LWCRE (Fig. 21).

As the changes in shortwave cloud radiative forcing (SWCRE) and LWCRE nearly compensate each other, the net total radiative effect at TOA $\left(F_{\text {net }}\right)$ only differs by $0.2-$ $0.3 \mathrm{~W} \mathrm{~m}^{-2}$ between CTRL and PROG, which corresponds to the interannual variability (not shown). Note that CTRL is tuned to be in equilibrium and it is rather remarkable that without any further tuning the new prognostic scheme results in a similar climate. Furthermore, the TOA shortwave (SW) and long-wave (LW) radiation of PROG are in better agreement with the newest estimates presented by Wild et al. (2013).

The aerosol optical depth (AOD) has been reduced in PROG by around $15 \%$ with respect to CTRL and is certainly related to the prognostic treatment of precipitation. Primarily, the precipitation takes longer to reach the surface and can therefore be a more effective sink through wet deposition. Further changes in precipitation amount, through altered collection rates, or the hydrological cycle can influence the frequency with which aerosol particles are washed out. This also shows that isolating the direct radiative effect of the aerosols (ERFari; Boucher et al., 2013) from the indirect effects on clouds (ERFaci) is very difficult, since both effects act at the same time (Lohmann et al., 2010). Consequently, we prefer to only estimate the total radiative effect (ERFari + aci).

\subsubsection{Cloud properties}

The introduction of a prognostic precipitation scheme has a particularly strong influence on the CIWP and the ICNC burden. Figure 3 shows the zonal mean cloud ice water content (CIWC) which has not only increased in PROG compared to CTRL, but illustrates that ice clouds are more frequent in lower altitudes, in particular close to the annual mean melting line. Compared to annual mean ERAinterim reanalysis (Dee et al., 2011) for the years 20002011 and ensemble mean satellite observations of CloudSat and CALIPSO (Cloud-Aerosol Lidar and Infrared Pathfinder Satellite Observations) (Li et al., 2012), the known underestimation of CIWC by the ECHAM5-HAM model is clearly visible. However, the higher CIWC values in PROG and the shift to lower altitudes is in better agreement with both ERAinterim reanalysis and satellite observations. Consequently, the reduced LWCRE using prognostic precipitation is also due to the lower lying ice clouds. As the ICNC burden is reduced with higher CIWC, the average ice crystal size is larger and therefore ice crystals sediment faster, resulting in clouds at lower altitudes. The reason for the reduced ICNC burden is caused by a change in collection rates and will be addressed later. Note that the ERA-interim reanalysis is based on model physics, but by using data assimilation, the comparison to the satellite observations is better. On the other hand, as discussed in more detail in Li et al. (2012), caution is also war-
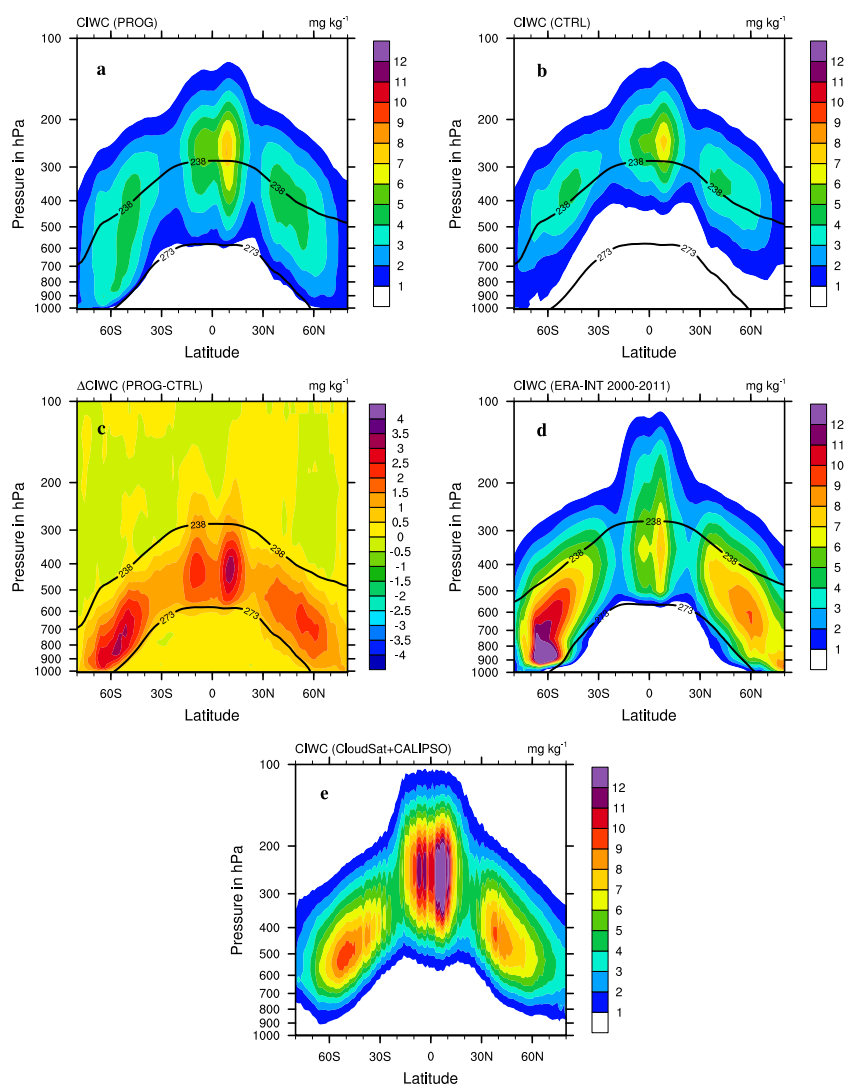

Figure 3. Annual mean ice water content of (a) PROG, (b) CTRL, (c) the difference PROG - CTRL, (d) ERA-interim reanalysis, and (e) CloudSat + CALIPSO, ensemble mean satellite observations of CloudSat and the Cloud-Aerosol Lidar and Infrared Pathfinder Satellite Observations ( $\mathrm{Li}$ et al., 2012). The solid black lines in (a)(d) represent the melting and the homogeneous freezing levels at $T=273$ and $T=238 \mathrm{~K}$, respectively.

ranted for the satellite observations of mixed-phase clouds in mid- and high latitudes, where the contributions of ice and liquid water are difficult to distinguish. Consequently, the reanalysis cannot be seen as the truth, but it illustrates a suitable and plausible description of the current climate.

For the cloud liquid water content (CLWC) shown in Fig. 4 the prognostic treatment has lead to an overall reduction. Comparing zonal mean CLWC in PROG and CTRL (cf. Fig. 4a and b), CTRL has a higher CLWC, especially in midlatitudes and above the mean melting line. Note that the annual mean melting lines are only given as a guidance for the comparison to the CIWC. With respect to the ERA-interim reanalysis clear differences are seen; in the midlatitudes both PROG and CTRL overestimate the CLWC, whereas towards the tropics the low altitude clouds are missing and CLWC at higher altitudes is overestimated. Although PROG shows a tendency to have a few more liquid water clouds at lower altitudes in the subtropics, there are too many liquid water 

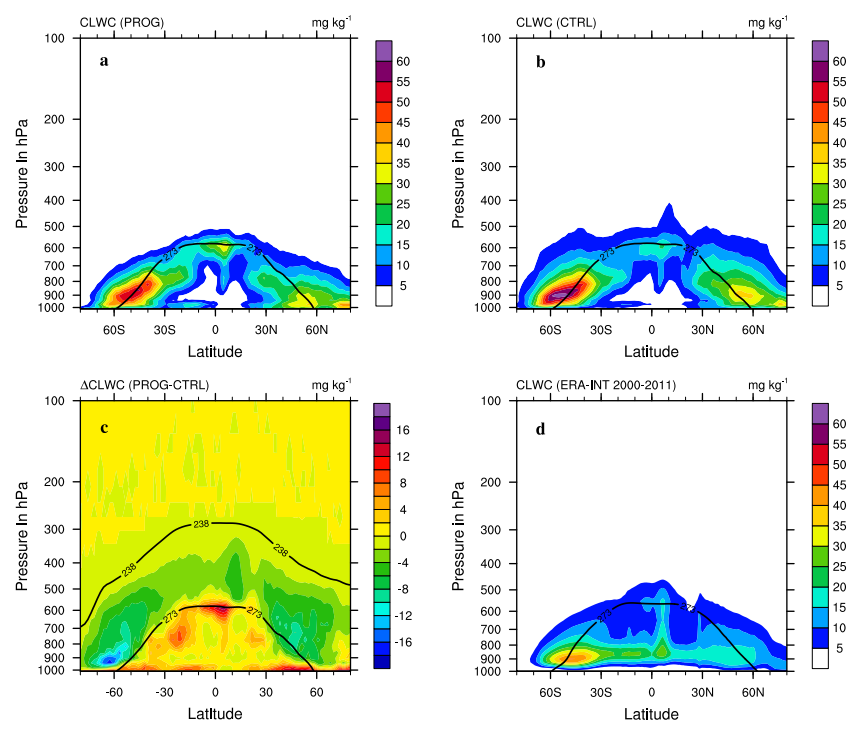

Figure 4. Annual mean liquid water content of (a) PROG, (b) CTRL, (c) the difference PROG - CTRL, and (d) ERA-interim reanalysis, where the solid black lines represent the melting and the homogeneous freezing (only in c) levels at $T=273$ and $T=238 \mathrm{~K}$, respectively.

clouds close to the surface, a bias already exhibited by CTRL that remains to be addressed.

The CLWC difference between the two model versions (cf. Fig. 4c) shows that below the melting line CLWC is enhanced in PROG, but reduced above it. The hypothesis is that due to the higher CIWC in general and particularly above the melting layer, supercooled liquid water is more rapidly depleted trough the Wegener-Bergeron-Findeisen (WBF) process in PROG compared to CTRL. The difference in relative humidity depicted in Fig. 5a helps to underline this hypothesis as large regions above the melting layer are dryer by up to $6 \%$. On one hand, this correlates with the higher CIWC values and on the other hand, it makes the formation of new liquid water clouds less probable, as a relative humidity based cloud cover scheme is used (Sundqvist et al., 1989). Conversely, the enhanced CLWC in the tropics can be explained by the enhanced relative humidity in the regions below the melting layer of up to $3 \%$, the reasons for which have not been clarified yet. Figure $5 \mathrm{~b}$ also shows the difference in cloud cover between PROG and CTRL, which although small (below $\pm 3 \%$ ), is dominated by the reduction of ice clouds in the midlatitudes and enhanced liquid clouds in the tropics.

\subsubsection{Precipitation microphysics}

With the introduction of prognostic precipitation (PROG), the global mean precipitation rate did not change much compared to the reference simulation (CTRL). However, as precipitation is balanced by the amount of evaporation and we
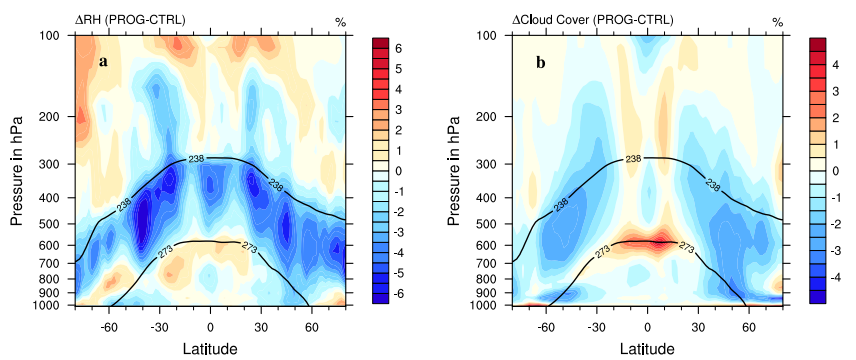

Figure 5. Annual mean difference in (a) RH and (b) TCC of PROG-CTRL, respectively. The solid black lines in (a) represent the melting and the homogeneous freezing levels at $T=273$ and $T=238 \mathrm{~K}$, respectively.

are using climatological SSTs, which determine the evaporation rates over the ocean, this is not surprising. Nevertheless, the microphysical processes related to precipitation may well be altered: (i) by the introduction of a third liquid water class, i.e., drizzle, and the altered collection rates, and (ii) by the time splitting of the precipitation related microphysics.

In contrast to the diagnostic treatment in CTRL, PROG keeps precipitation in the atmosphere from one time step to the next. Figure $6 \mathrm{a}-\mathrm{c}$ show the drizzle, rain and snow water content (DWC, RWC and SWC, respectively), with the contour lines of the CLWC and the CIWC overlaid. The highest DWC is found in the midlatitudes, which correlate well with the largest values in CLWC, as expected. The values are larger at lower altitudes due to the effect of gravitational sorting. For the RWC the values are 1 order of magnitude larger, not only because of the larger drop sizes, but also, in particular, because of the additional source from the melting of snow. Especially in the tropics this is the case, where the RWC correlates better with the CIWC and SWC than with the CLWC. As expected, the SWC is well correlated with the CIWC, since it is the primary source for snow. The largest values are just above the melting line, again not only an effect of the gravitational sorting but also due to the continuous accretion of ice and liquid water, since the accretion rate is temperature dependent and larger at warmer temperatures. Below the melting line the SWC decreases rapidly, where it melts and forms rain. Compared to other studies (Reitter et al., 2011; Wang et al., 2011; Gettelman et al., 2015), the amount of snow in the atmosphere is an order of magnitude smaller. The reason for which could be the treatment of the collection processes, melting or sedimentation. Future work will address this issue.

To assess the effects of changes in the microphysics, for both the liquid and ice phase, and the introduction of prognostic precipitation, 6-hourly data of the year 2000 for both PROG and CTRL were used for further analysis. For mean values the whole year was used, whereas for instantaneous values 1 month of data revealed to be a sufficiently long time period for good statistics. For the latter case, dependence on the season was found to be negligible. We arbitrarily chose 

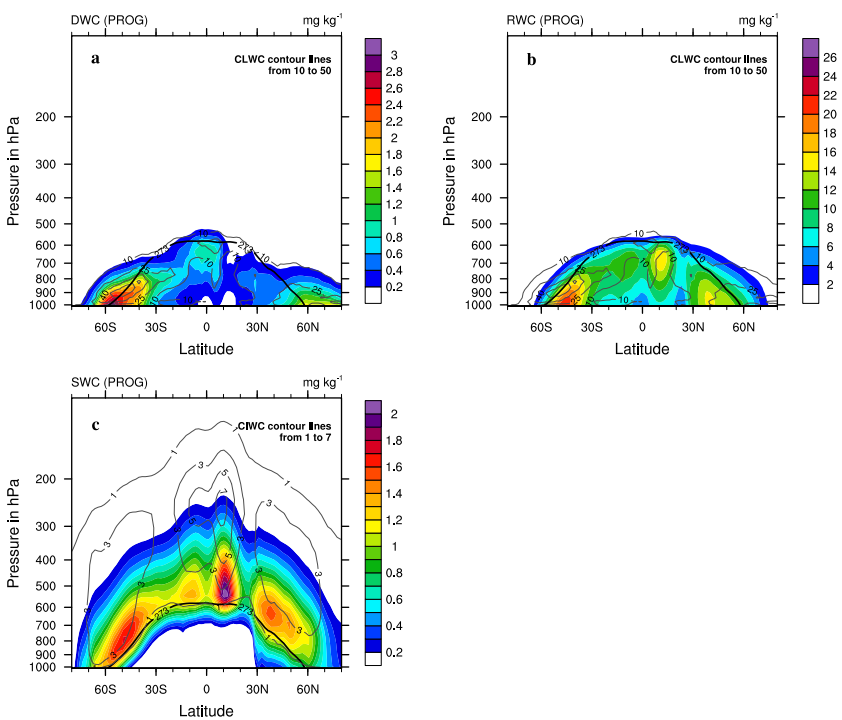

Figure 6. Annual mean precipitation water contents from PROG of (a) drizzle and (b) rain with the contour lines of the CLWC, such as (c) snow with the contour lines of the CIWC and the melting line (solid black line).

the month of July to make sure of no remnant influence from spin-up.

For the collection processes in the liquid phase, the mean vertically integrated cloud autoconversion $\left(\mathrm{AU}=\mathrm{aut}_{\mathrm{c}}\right)$ and accretion rates $\left(\mathrm{AC}=\mathrm{ac}_{\mathrm{cd}}+\mathrm{ac}_{\mathrm{cr}}\right)$ are shown in Figs. 7 and 8 for CTRL and PROG, respectively. Figure 7 shows that AU and $\mathrm{AC}$ in the CTRL simulation are comparable such that the fraction of $\mathrm{AU}$ to the total conversion rate $(\mathrm{AU}+\mathrm{AC})$ is well above $30 \%$ in most regions. It increases with increasing stratiform precipitation and therefore increases towards high latitudes (cf. Fig. 2). This overestimation of AU is well known in global models with diagnostic treatment of rain (e.g., Posselt and Lohmann, 2008a; Gettelman et al., 2013). By introducing the prognostic treatment of drizzle and rain in PROG the fraction of $\mathrm{AU}$ to the total conversion rate is strongly reduced to values well below $6 \%$ as can be seen in Fig. 8. Although AU is of similar magnitude, AC has increased drastically. The global mean burdens are given in Table 3 and illustrate these conclusions again. Effectively, AC has increased by nearly 2 orders of magnitude from CTRL to PROG, the reasons for which is the longer lifetime of drizzle and rain in the cloud.

To understand the differences in AU from CTRL to PROG, instantaneous values of $\mathrm{AU}$ as a function of the mean effective cloud droplet radius for both CTRL and PROG are shown in Fig. 9. At large mean radii, the autoconversion rates of PROG are an order of magnitude higher than in CTRL. However, the triclass scheme in PROG exhibits a threshold type behavior, such that below an effective radius of $10 \mu \mathrm{m}$ the amount of mass transferred to drizzle is negligible. While such a threshold does not exist in nature, model studies and
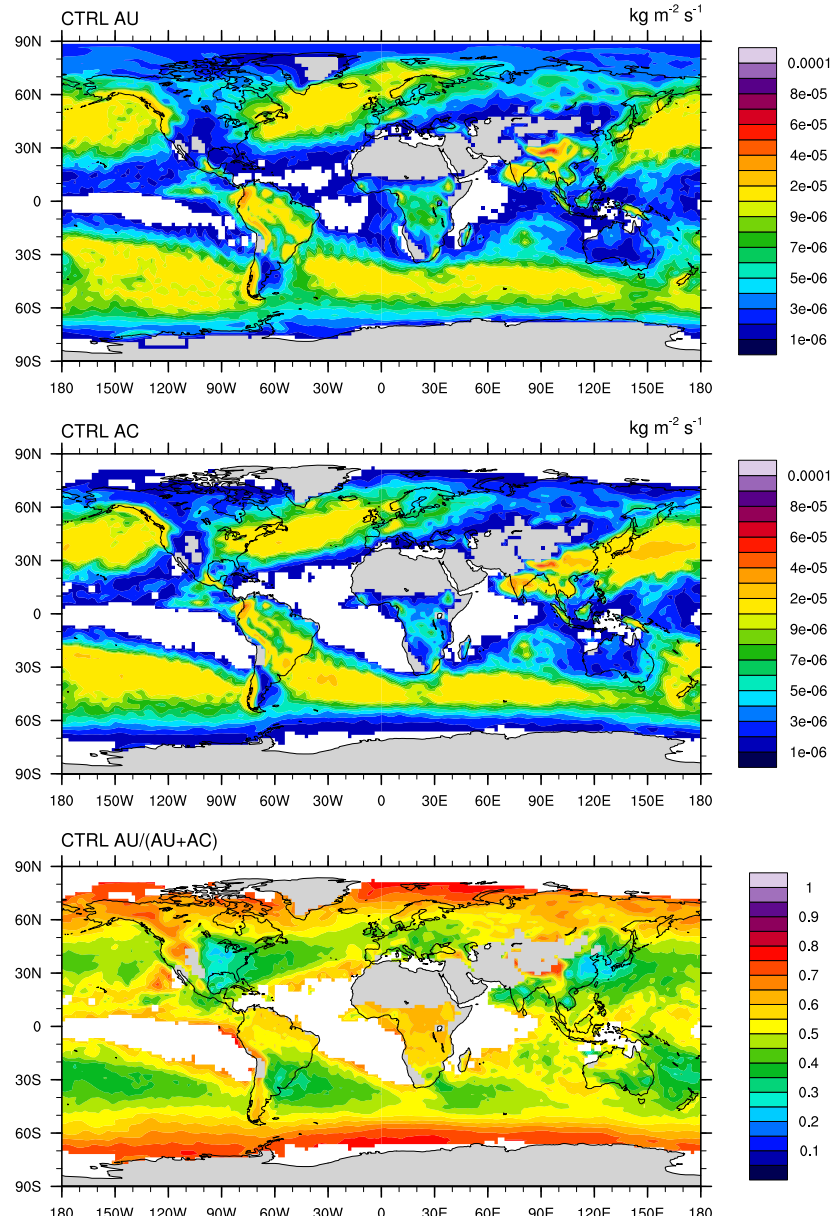

Figure 7. Mean vertically integrated autoconversion (AU) and accretion rates (AC) of CTRL for the year 2000, such as the fraction of $\mathrm{AU}$ to the total collection rate $(\mathrm{AU}+\mathrm{AC})$.

observations suggest that cloud droplets need to grow beyond $12-14 \mu \mathrm{m}$ for a significant amount of rain to be produced (Rosenfeld et al., 2012), i.e., for growth by collisioncoalescence to dominate over diffusional growth. CTRL has a more gradual decrease and has autoconversion rates which are several orders of magnitude larger than PROG at effective radii below $10 \mu \mathrm{m}$. Although, one may argue that this is needed to produce a realistic amount of rain in a diagnostic scheme, it is not physical. Thus, the new prognostic scheme allows for a more physical representation not only of the sedimentation of hydrometeors, but consequently also for the microphysical processes.

For the ice phase the mean vertically integrated aggregation ( $\mathrm{AG}$ is agg) and accretion ( $\mathrm{ACi}$ is $\mathrm{ac}_{\mathrm{s}}$ ) rates are shown in Figs. 10 and 11 for CTRL and PROG, respectively. In contrast to the liquid phase, $\mathrm{ACi}$ is lower than $\mathrm{AG}$ in both simulations, such that AG makes up around $74 \%$ and even $86 \%$ of the total collection rate in the global mean for CTRL and PROG, respectively (cf. Table 3). The values for AG and ACi have both increased by 1 or nearly 2 orders of magnitude in 

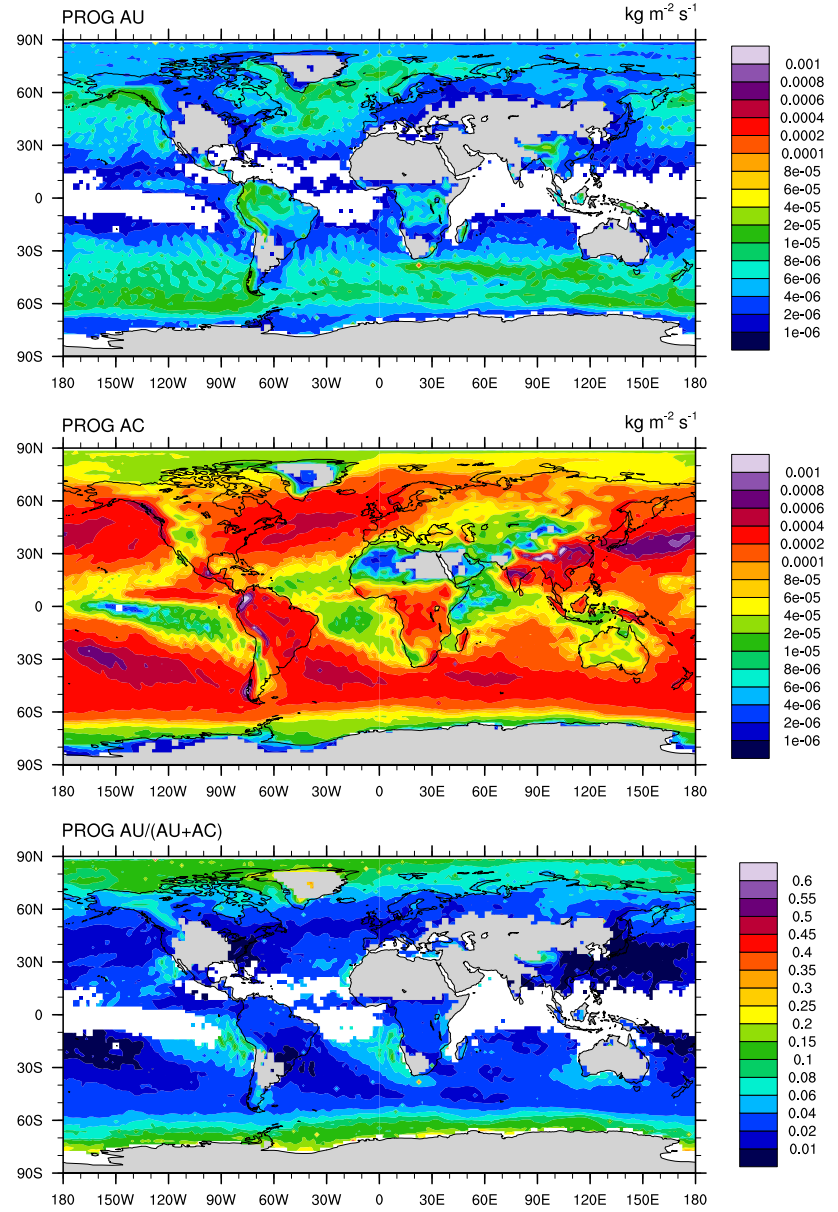

Figure 8. Mean vertically integrated autoconversion (AU) and accretion rates (AC) of PROG for the year 2000, such as the fraction of $\mathrm{AU}$ to the total collection rate $(\mathrm{AU}+\mathrm{AC})$.

Table 3. Global annual mean conversion rate burdens for both cloud liquid and ice for CTRL and PROG for the year 2000.

\begin{tabular}{lrrr}
\hline & & PROG & CTRL \\
\hline $\mathrm{AU}\left(=\mathrm{au}_{\mathrm{c}}\right)$ & $\left(\mathrm{kg} \mathrm{m}^{-2} \mathrm{~s}^{-1}\right)$ & $3.9 \times 10^{-6}$ & $5.2 \times 10^{-6}$ \\
$\mathrm{AC}\left(=\mathrm{ac}_{\mathrm{cd}}+\mathrm{ac}_{\mathrm{cr}}\right)$ & $\left(\mathrm{kg} \mathrm{m}^{-2} \mathrm{~s}^{-1}\right)$ & $1.6 \times 10^{-4}$ & $5.2 \times 10^{-6}$ \\
$\mathrm{AU} /(\mathrm{AU}+\mathrm{AC})$ & $\%$ & 2.3 & 50.0 \\
$\mathrm{AG}(=\mathrm{agg})$ & $\left(\mathrm{kg} \mathrm{m}^{-2} \mathrm{~s}^{-1}\right)$ & $2.9 \times 10^{-4}$ & $6.8 \times 10^{-6}$ \\
$\mathrm{ACi}\left(=\mathrm{ac}_{\mathrm{s}}\right)$ & $\left(\mathrm{kg} \mathrm{m}^{-2} \mathrm{~s}^{-1}\right)$ & $4.6 \times 10^{-5}$ & $2.5 \times 10^{-6}$ \\
$\mathrm{AG} /(\mathrm{AG}+\mathrm{ACi})$ & $\%$ & 86.4 & 73.6 \\
\hline
\end{tabular}

PROG, which is mainly due to the large increase in CIWC, but also because of the occurrence of cloud ice at lower altitudes, since both $\mathrm{AG}$ and $\mathrm{ACi}$ increase at warmer temperatures. This increase stems from the increase in the quasiliquid layer with increased temperature, in turn causing the sticking efficiency to increase. Since the ratio of AG/ACi is not known on these scales and constitutes a combination of complex processes, which also depend on the representation

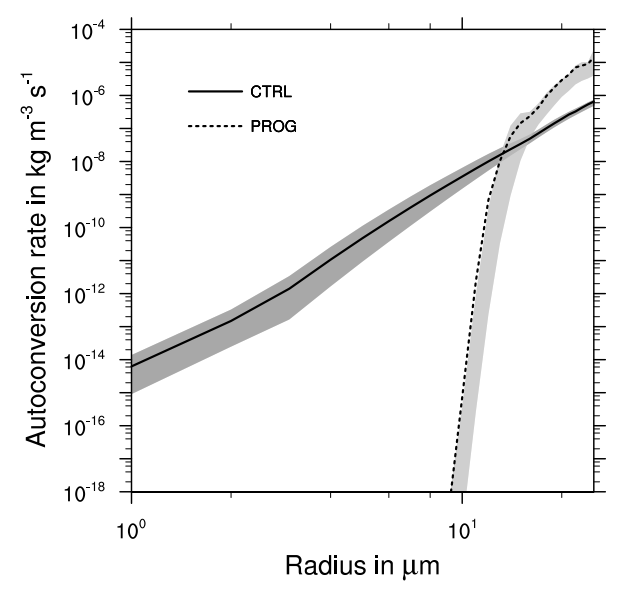

Figure 9. Dependence of autoconversion rate on effective cloud droplet radius for the month of July 2000. The lines denote the mean and the gray areas depict the range between the 10th and 90th percentile, respectively.

of the ice phase (Morrison and Grabowski, 2008), we cannot conclude whether the prognostic treatment of snow has lead to a more realistic treatment of the ice phase processes. Nevertheless, these results suggest that within the framework of a prognostic precipitation scheme, AG plays the dominant role in the total collection rate. However, note that as the actual collection processes for the ice phase have not been changed from CTRL to PROG, an overestimation of AG or ACi cannot be excluded due to the applied time splitting. The suitability of the collection processes needs to be further tested, e.g., whether the assumption of a smallest snow crystal size in the aggregation process needs to be adjusted under a prognostic scheme (Eidhammer et al., 2014).

To quantify the effect of prognostic precipitation on observable variables, Fig. 12a-c show the frequency of occurrence of instantaneous surface precipitation (from stratiform clouds), CLWP and CIWP, respectively, for both CTRL and PROG. The distribution of instantaneous surface precipitation in PROG has become broader and the peak values around $0.8 \mathrm{~mm} \mathrm{day}^{-1}$ are strongly reduced compared to CTRL. Although the occurrence of rates below $0.1 \mathrm{~mm} \mathrm{day}^{-1}$ has increased in PROG, the contribution to the overall surface precipitation amount is negligible. However, a larger contribution is due to the slight increase of precipitation rates above $0.2 \mathrm{~mm} \mathrm{day}^{-1}$, which together with the increased amount of precipitation events (about 15\%) could explain the increased stratiform precipitation amount in PROG. Overall, the prognostic treatment of precipitation has reduced the amount of light rain events around $1 \mathrm{~mm} \mathrm{day}^{-1}$, similar to what was achieved for the Met Office Unified Model (MetUM) by Walters et al. (2014). The distribution of instantaneous CLWP (cf. Fig. 12b) has slightly shifted to larger values in PROG. However, as there are a smaller number of values in PROG this shift is not signifi- 
cant. In Fig. 12c the distribution of instantaneous CIWP values differs between both simulations. CTRL exhibits a very distinct peak around $60 \mathrm{~g} \mathrm{~m}^{-2}$ and a shoulder all the way down to around $10 \mathrm{~g} \mathrm{~m}^{-2}$. In PROG the CIWP has a broader, slight bimodal distribution with a maximum at $30 \mathrm{~g} \mathrm{~m}^{-2}$ and a smaller peak at $110 \mathrm{~g} \mathrm{~m}^{-2}$. For CIWP below $10 \mathrm{~g} \mathrm{~m}^{-2}$ the distributions are very similar. We believe that the cut-off behavior towards larger values in CTRL is related to the higher lying ice clouds as seen in Fig. 3b. With more ice clouds in the mixed-phase region, i.e., between the melting and homogeneous freezing level, the ice crystals can grow larger and hence lead to larger CIWP values. Thus, the tail of larger values in PROG corresponds to the increased global annual mean CIWC values discussed before (cf. Fig. 3a). Note that these overall conclusions of Fig. 12 can also be drawn for a different month or region, i.e., tropics, midlatitudes or ocean and land (not shown).

To further assess the effect of prognostic precipitation on the hydrological cycle, Fig. 13 presents all the relevant sources and sinks for the large-scale liquid and ice clouds of CTRL and PROG for the year 2000. The global mean values of surface evaporation, precipitation and the water paths are very similar to the multi-annual global means presented in Table 2, which suggests that the rates would not change much for an analysis over a longer time period. Due to the use of climatological SSTs the amount of surface evaporation is very similar in both simulations and is balanced by the amount of convective and large-scale precipitation. The reduced CLWP in PROG is mainly due to the strongly reduced condensation rate from $18.2 \mathrm{mg} \mathrm{m}^{-2} \mathrm{~s}^{-1}$ in CTRL to $8.6 \mathrm{mg} \mathrm{m}^{-2} \mathrm{~s}^{-1}$ in PROG. This is connected to smaller amounts of CLWC in higher altitudes (cf. Fig. 4a) and is underlined by the enhanced WBF process, which has increased by $30 \%$. Consequently, PROG produces less warm phase precipitation than CTRL on a global mean. In contrast, the increase in CIWP is largely due to the increased deposition rate in PROG, which has nearly doubled with respect to CTRL. Again, this is correlated to the larger vertical extent of the CIWC mentioned before, but is probably also due to the longer residence time of the CIWC allowing for larger gain by deposition and the WBF process; accordingly, the amount of freezing and sedimentation is reduced. With the larger CIWP the rate of sublimation, melting and snow production has increased substantially from CTRL to PROG. Interestingly, in PROG the amount of cloud liquid water accreted by snow has reduced drastically to $0.6 \mathrm{mg} \mathrm{m}^{-2} \mathrm{~s}^{-1}$ compared to $7.5 \mathrm{mg} \mathrm{m}^{-2} \mathrm{~s}^{-1}$ in CTRL. We believe this is simply due to the reduced amount of cloud water above the melting layer, which again is coupled to the source rates for cloud ice. It is difficult to say which process is mainly responsible for the decrease in CLWP or the increase in CIWP in PROG, as all act together. Finally, the enhanced large-scale precipitation rate in PROG is ultimately due to the larger primary production of snow (around 50\%) and the smaller sublimation rates. For the warm phase precipitation, the amount of loss due to
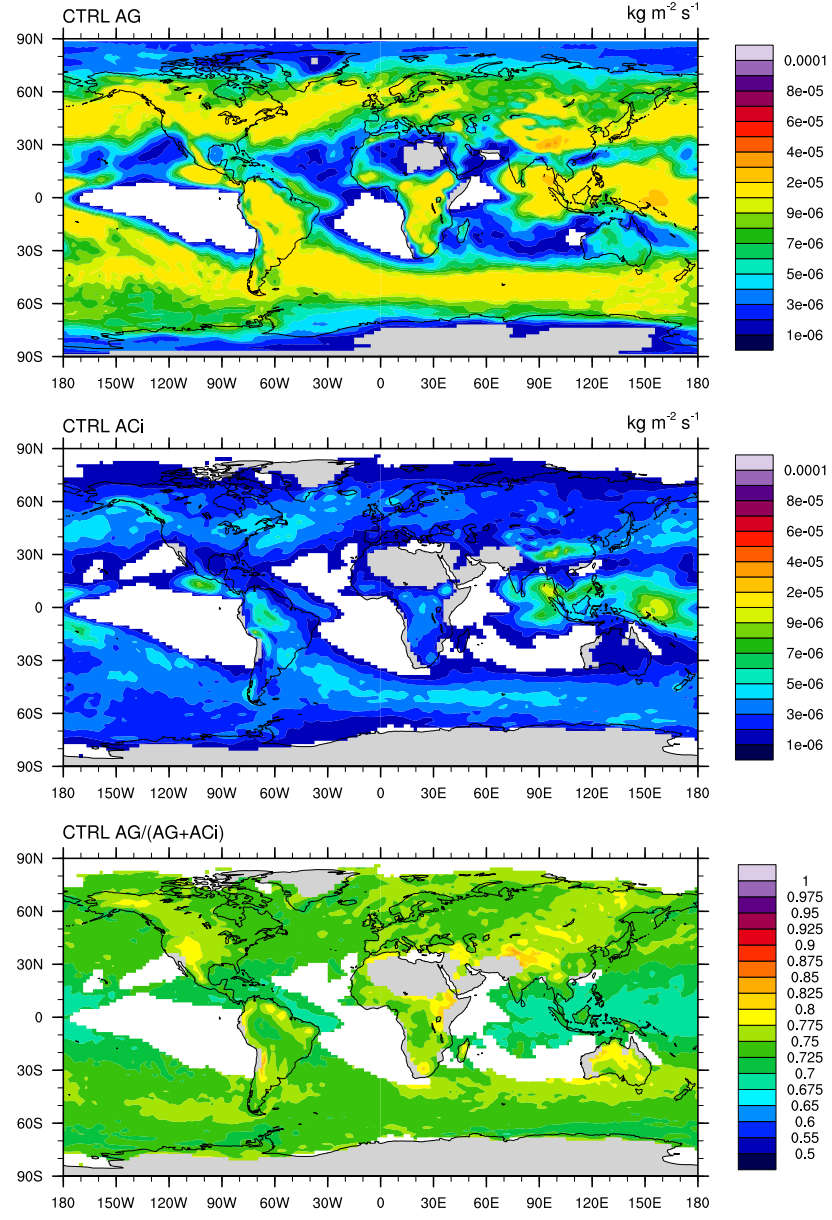

Figure 10. Mean vertically integrated aggregation (AG) and (ice) accretion rates (ACi) of CTRL for the year 2000, such as the fraction of $\mathrm{AG}$ to the total collection rate $(\mathrm{AG}+\mathrm{ACi})$.

evaporation is just above $65 \%$ for both CTRL and PROG. On the other hand, the amount of sublimation is reduced from $34 \%$ for CTRL to $4 \%$ for PROG. The reduced relative humidity above the melting level (cf. Fig. 5a), which is correlated to the larger vertical extent of CIWC, is certainly one reason, but others processes related to the prognostic treatment, such as sedimentation, will need to be addressed in future work. Dividing CLWP or CIWP by the sum of all sources or sinks given in Fig. 13 yields the cloud lifetimes for liquid $\tau_{\text {liq }}$ or ice $\tau_{\text {ice }}$ clouds, respectively. $\tau_{\text {liq }}$ slightly increased from CTRL to PROG from 0.6 to $0.7 \mathrm{~h}$, whereas $\tau_{\text {ice }}$ remains the same. The conclusion is that with the introduction of prognostic precipitation, the speed of the hydrological cycle is not changed, but internal conversion rates are altered and lead to a redistribution of cloud liquid and ice. Gettelman et al. (2015) reported similar findings with respect to the conversion rates, but in contrast found that the CIWP is strongly reduced. 

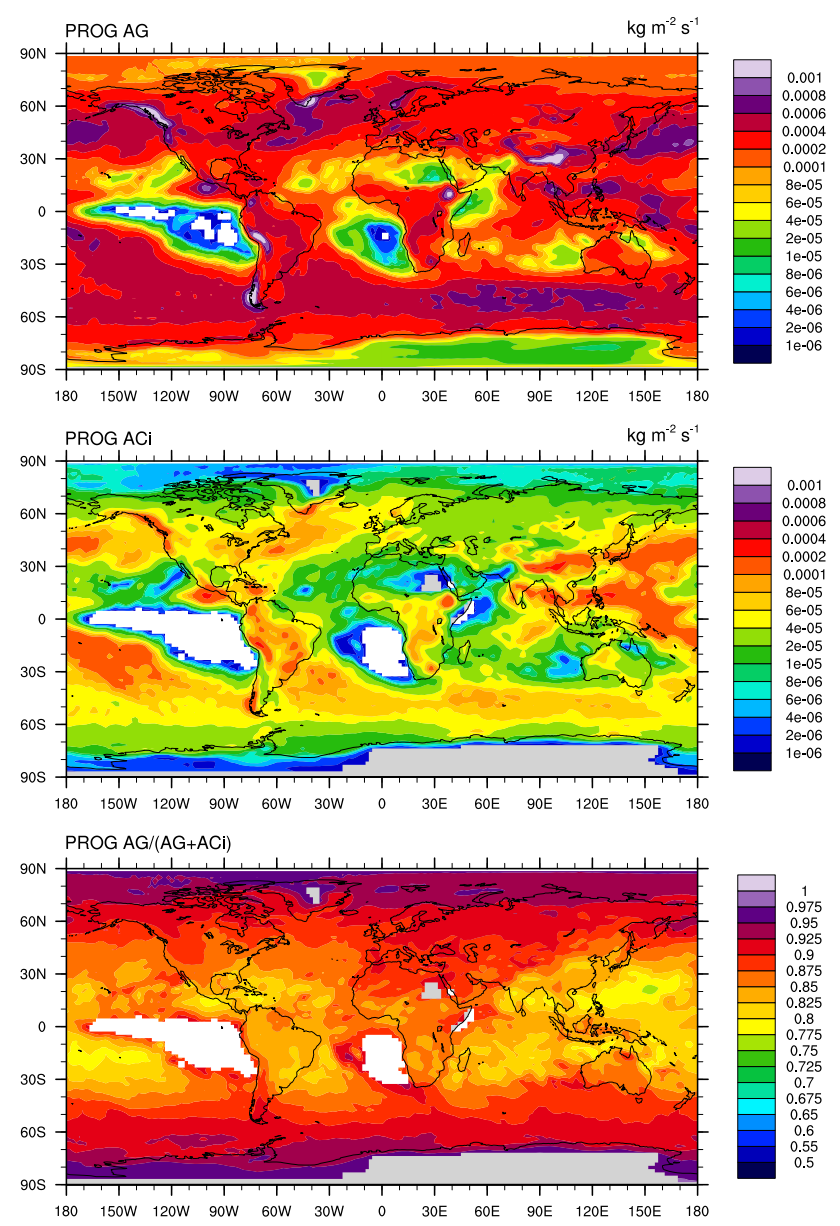

Figure 11. Mean vertically integrated aggregation (AG) and (ice) accretion rates (ACi) of PROG for the year 2000, such as the fraction of $\mathrm{AG}$ to the total collection rate $(\mathrm{AG}+\mathrm{ACi})$.

\subsection{Present-day vs. pre-industrial climate}

To evaluate the total anthropogenic aerosol effect, preindustrial (PI) simulations where performed for both CTRL and PROG. Global annual mean values are also summarized in Table 2 and the differences (PD - PI) in zonal annual means of selected quantities are shown in Fig. 14.

The differences from PD to PI in global annual mean precipitation amount and TCC are small, i.e., on the order of a few percent in both CTRL and PROG and is mainly due to the use of climatological SSTs as mentioned before. Consequently, the slight increase in precipitation and slight reduction in TCC cannot be attributed to a specific process.

The CLWP and CDNC burden have increased significantly in the Northern Hemisphere due to the increase in aerosol concentration from PI to PD for both CTRL and PROG. Although PROG reduces these increases compared to CTRL, it is not as pronounced as a factor of 2 found in a previous study (Posselt and Lohmann, 2009). The increases in CLWP and CDNC burden lead to an increase in SWCRE as shown in Fig. 14a, c and e. In addition to the total water path, the SWCRE is also influenced by TCC (cf. Fig. 14b), which could explain the double peak in the Northern Hemisphere of the SWCRE change in PROG. However, as these changes in TCC are below $1 \%$, the interpretation is to be taken with caution. Furthermore, note that the change in TCC at the Equator - although small - has opposite signals in PROG and CTRL, leading to a $1 \mathrm{~W} \mathrm{~m}^{-2}$ difference in SWCRE between PROG and CTRL.

The change in LWCRE (cf. Fig. 14f) is rather noisy and not significant in a global mean, but seems to correlate with the change in CIWP, which has not changed significantly either (not shown). Interesting is that the rather large change in ICNC burden in CTRL (approximately $14 \%$ with respect to $\mathrm{PD}$ in a global mean) has little effect on the radiation balance (cf. Fig. 14d and f). On the other hand, the changes in ICNC burden in PROG are negligible.

The total net radiative effect of the anthropogenic aerosol forcing (ERFari + ari) in terms of TOA energy balance $\left(\Delta F_{\text {net }}\right)$ is a negative effect of around $-1.3 \pm 0.3 \mathrm{~W} \mathrm{~m}^{-2}$ for CTRL and $-1.6 \pm 0.3 \mathrm{~W} \mathrm{~m}^{-2}$ for PROG, where the error estimation corresponds to the interannual standard deviation. Both model versions overestimate the inverse estimate of $-1.1 \pm 0.4 \mathrm{~W} \mathrm{~m}^{-2}$ by Murphy et al. (2009) and fall towards the negative end of the ERFaci + ari estimate in Boucher et al. (2013). The difference of about $0.3 \mathrm{~W} \mathrm{~m}^{-2}$ between CTRL and PROG can mainly be attributed to the differences in the tropical and subtropical regions, where the change in $F_{\text {net }}$ is more negative for PROG (cf. Fig. 14g). Here, the reason for the enhanced CLWP and TCC in the tropics of PROG has not been clarified and will need further attention, but is likely related to the coupling of the large-scale clouds to the convective cloud scheme. In addition, considering that the tuning parameters in PROG are the same as in CTRL, except for the autoconversion and accretion rates altered by the new collection scheme, the difference in $F_{\text {net }}$ could be a measure of uncertainty in the current model setup, in particular for the tropics.

As the anthropogenic aerosol forcing mainly influences liquid water clouds, the change in shortwave radiation is dominant and leads to a net negative radiative forcing from PI to PD for both CTRL and PROG. Following Wang et al. (2011, cf. their Fig. 16) the sensitivity of the CLWP to changes in $\mathrm{CCN}$ concentrations is shown in Fig. 15a and b for CTRL and PROG, respectively. The figure shows box plots and linear regression lines of the relative changes $[(\mathrm{PD}-\mathrm{PI}) / \mathrm{PI}]$ in annual mean CLWP versus the relative changes in annual mean activated $\mathrm{CCN}$ concentrations averaged over the lowest eight model levels (surface to about $800 \mathrm{hPa}$ ). From the regression lines it can be deduced that with the prognostic treatment of precipitation a $25 \%$ decrease in slope, and hence, lower sensitivity of the CLWP to the aerosol forcing can be achieved. Furthermore, the resulting slope in PROG is very similar to the slope of 0.11 found by Wang et al. (2011) using the multi-scale modeling 

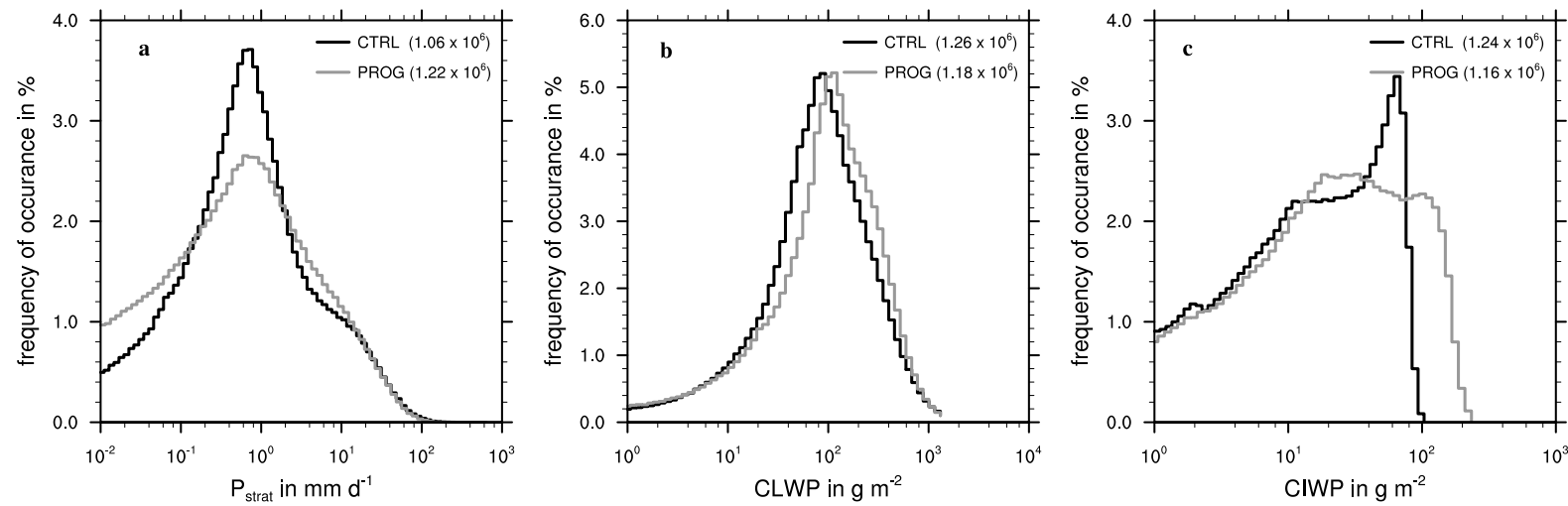

Figure 12. Frequency of occurrence of instantaneous (a) large-scale surface precipitation rate, (b) liquid water path and (c) ice water path for the month of July 2000 for both CTRL (black line) and PROG (gray line) simulations. Note that the $x$ axes are in logarithmic scale and the numbers in the brackets correspond to the total number of events plotted.

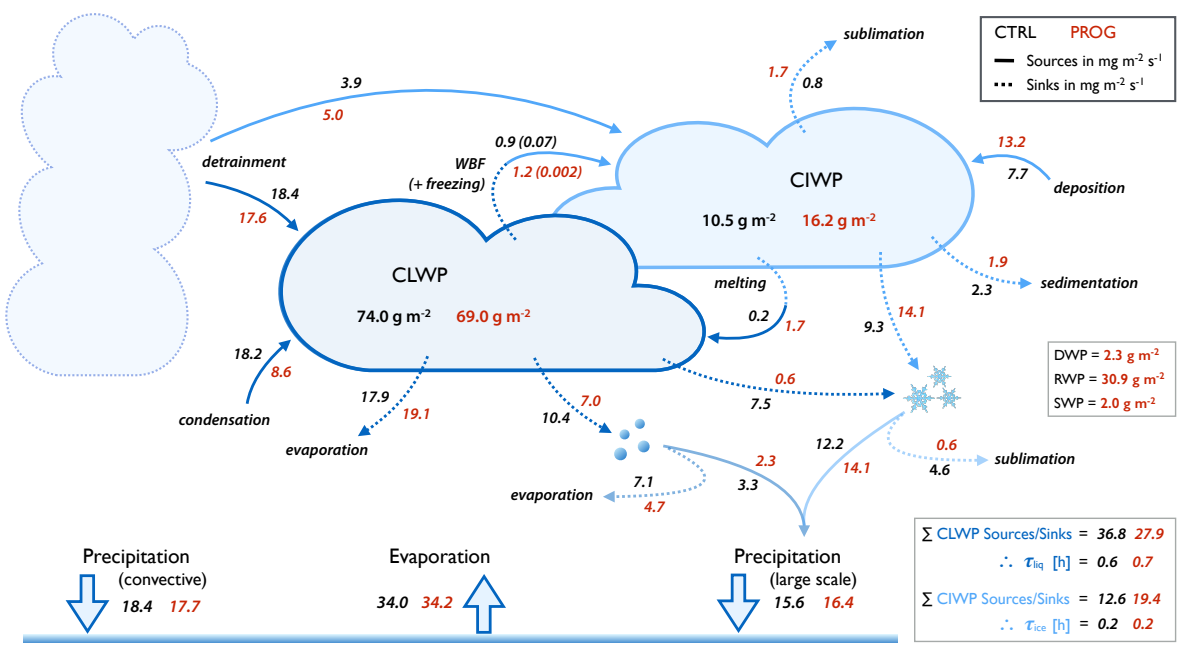

Figure 13. Illustration of the hydrological cycle with all relevant global annual mean (vertically integrated) conversion rates and the cloud lifetimes of CTRL (black) and PROG (red numbers) for the year 2000.

framework (MMF) model. The spread in change of CLWP at low relative changes in $\mathrm{CCN}$ is slightly larger in PROG than for CTRL, but at larger values the spread in CTRL is notably larger. In fact, for CTRL the larger the relative change in $\mathrm{CCN}$ the larger and broader the relative change in CLWP becomes, whereas for PROG the spread tends to become narrower. In PROG the spread of the data tends to level off, but not necessarily the mean values (illustrated by the stars in Fig. 15a and b). The Pearson correlation coefficients are low for both simulations, due to the data being localized between -0.25 and 1.0 in relative change of CCN. However, particularly for PROG where the data tend to level off, the lower correlation coefficient could be an indication that a linear regression might not be the most appropriate. Overall, the result compares well to the study performed by Wang et al. (2011) and is encouraging regarding the use of prognostic precipitation.
It may seem counter-intuitive that the sensitivity of the CLWP to the aerosol forcing is reduced with the prognostic treatment, but at the same time increasing ERFaci + ari, i.e., making $F_{\text {net }}$ more negative. However, note that the sensitivity of the CLWP to changes in CCN concentrations is measured on a microphysical scale and is no measure for the amount and distribution of clouds over the whole earth, as is $F_{\text {net }}$. As discussed earlier, the introduction of prognostic precipitation affects the conversion rates within the hydrological cycle and leads to a redistribution of cloud liquid and ice, which in turn depends on the model physics (cf. Gettelman et al., 2015). Herein lies the difficulty and further research investigating the coupling of prognostic precipitation to the model physics is needed to improve the uncertainty in the anthropogenic aerosol forcing. 

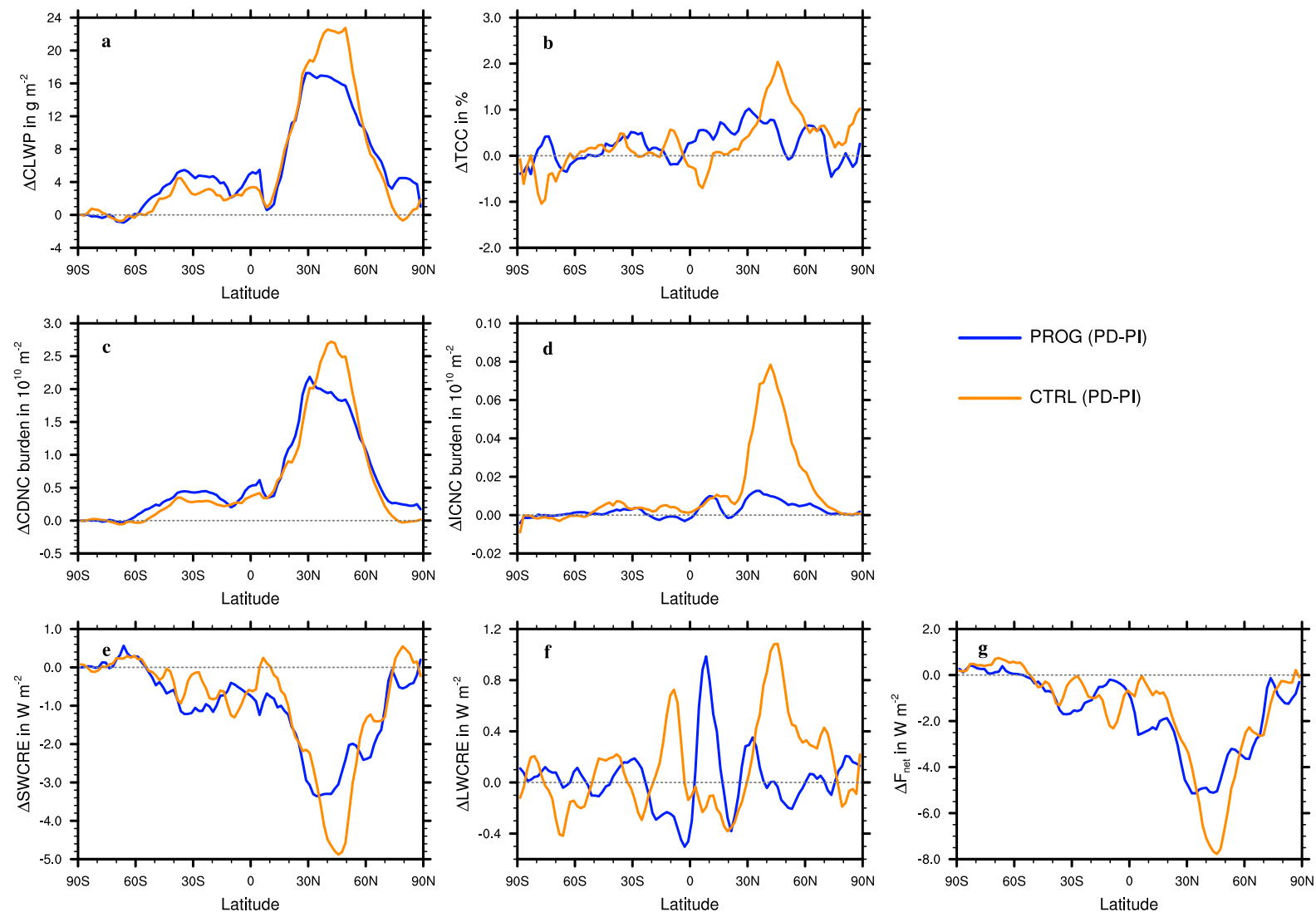

Figure 14. Zonal annual mean difference between PD and PI of (a) liquid water path, (b) total cloud cover, (c) the CDNC and (d) ICNC burden, (e) shortwave, (f) long-wave and (g) net TOA cloud radiative forcing for CTRL and PROG for the years 2000-2011.

\section{Conclusions}

We have introduced a prognostic precipitation scheme for both the liquid and ice phase for which the precipitation microphysics, i.e., melting and evaporation of precipitation, collection rates, and sedimentation, are subject to a time splitting. For the liquid phase, drizzle was introduced in addition to the existing cloud and rain water classes. Based on the triclass parameterization by Sant et al. (2013), the collection rates for autoconversion, accretion and self-collection were changed to account for the three classes. The ice phase microphysics scheme remained unchanged. Without any further tuning of the model the simulations compare well to observations and display clear improvements in modeled physics.

Improvements in the liquid phase are equivalent to other studies (Posselt and Lohmann, 2008a; Gettelman et al., 2015), where the prognostic treatment has lead to a better partitioning of the autoconversion and accretion rates, and subsequently to an improved sensitivity of the cloud liquid water path to the anthropogenic aerosol forcing. Furthermore, we were able to show, similar to Walters et al. (2014), that with the prognostic treatment of rain the frequency of light rain events can be reduced. Compared to the previous studies with two prognostic liquid water classes (Posselt and Lohmann, 2008a, 2009), the triclass scheme including drizzle does not significantly influence the resulting climate and under an anthropogenic aerosol forcing leads to similar reductions in CLWP and CDNC burden changes in the Northern Hemisphere as compared to a scheme with diagnostic precipitation. However, a prognostic scheme with three liquid classes is beneficial for certain applications. Following previous research on the effect of giant $\mathrm{CCN}$ on warm phase clouds (e.g., Saleeby and Cotton, 2004; Posselt and Lohmann, 2008b), giant CCN can act as a direct source for drizzle drops and would be well represented by such a scheme as it circumvents the problem of not being able to differentiate between the activation of smaller and larger drops. Furthermore, a simple coupling of drizzle to the radiative transfer calculations, by taking into account both cloud and drizzle water to determine the clout top effective radius as suggested by Wood (2000), may have an influence on the SWCRE of marine stratocumulus. In particular for pristine clouds, taking into account drizzle-sized drops $(>20 \mu \mathrm{m}$; Wood, 2000) was shown to be very important in determining the optical properties of the cloud. Under the current model setup first tests of these effects have been undertaken, but 

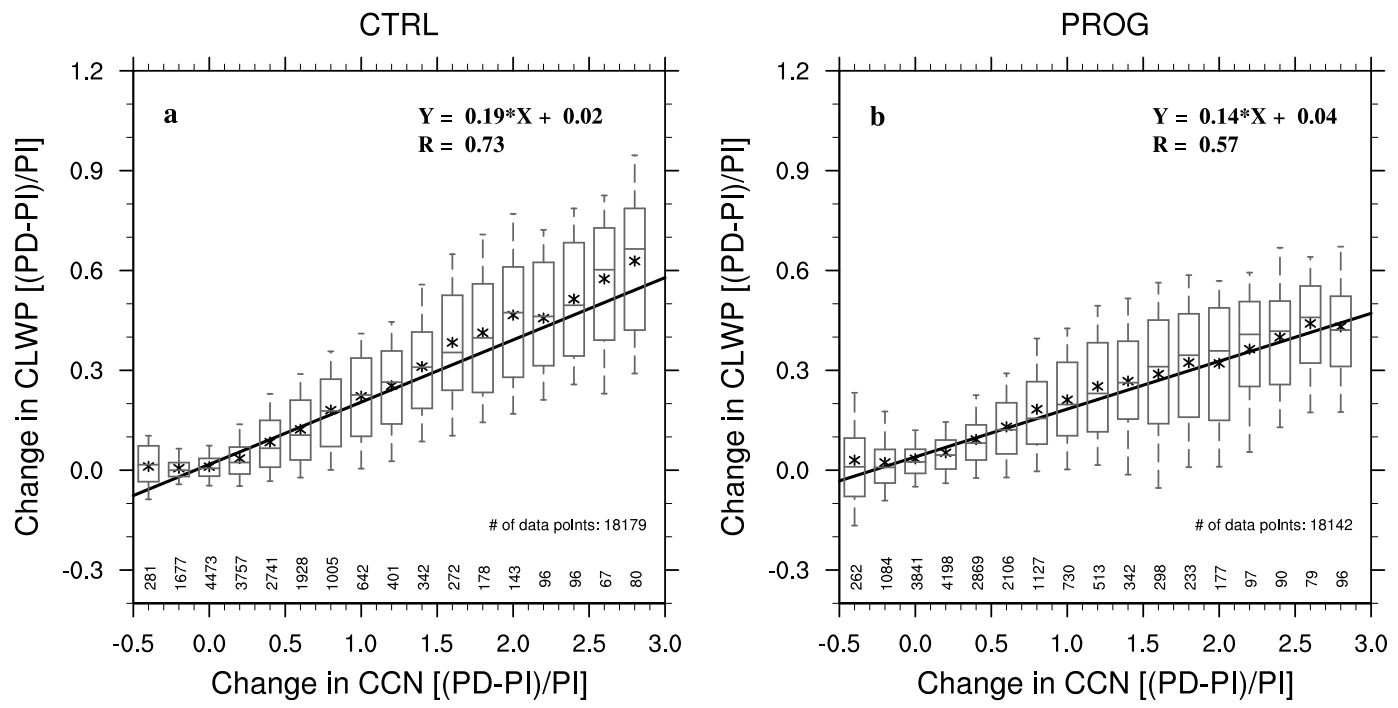

Figure 15. Box plots and linear regression lines of the relative changes $[(\mathrm{PD}-\mathrm{PI}) / \mathrm{PI}]$ in annual mean CLWP vs. the relative changes in annual mean activated CCN concentrations for the (a) CTRL and (b) PROG simulations, following the analysis by Wang et al. (2011). CCN concentrations are averaged over the lowest eight model levels (surface to about $800 \mathrm{hPa}$ ). The boxes represent the median (middle line) and the 25th and 75th percentile (lower and upper line, respectively), of the data within that bin. The whiskers show the 10th and 90th percentile (lower and upper whisker, respectively), and the stars represent the mean. The numbers above the $x$ axis represent the number of data points in a given bin. The linear regression lines and the Pearson correlation coefficients $(R)$ are given in the right upper corner.

have been surpassed by the effects due to the introduction of prognostic snow.

The implementation of a prognostic precipitation scheme has lead to a redistribution of cloud liquid and ice, reducing the amount of liquid clouds and increasing the amount of ice clouds, especially in lower altitudes. This is caused by a more effective growth of ice crystals by deposition and the Wegener-Bergeron-Findeisen (WBF) process. As a result, more ice water at lower altitudes produces more snow through enhanced aggregation and accretion rates. The speed of the hydrological cycle is not changed significantly, but changes in source and sink rates have altered the distribution of liquid and ice water in the atmosphere. As the description of the microphysical conversion processes for the ice phase were not changed with the introduction of prognostic snow, we do not exclude that adjustments may be necessary, especially in view of the rather small snow water mass compared to other studies (Reitter et al., 2011; Wang et al., 2011; Gettelman et al., 2015).

The effects of the prognostic scheme on the radiative budget of the liquid and ice clouds at the top of the atmosphere compensate each other, such that the radiation fluxes are rather well balanced. In particular, the global mean shortand long-wave radiation is in better agreement with observations. The prognostic treatment of liquid and solid phase precipitation is certainly more physical, as models tend to go to smaller and smaller resolutions in both time and space. Moreover, the sensitivity of the liquid water path to changes in $\mathrm{CCN}$ concentrations is reduced, favoring a prognostic over a diagnostic treatment of precipitation when studying aerosol-cloud-precipitation interactions. Although the total net radiative effect of the anthropogenic aerosol forcing is slightly higher in PROG than in CTRL, the values are within the interannual variability. Furthermore, investigating the coupling of the large-scale to the convection scheme, since essential differences are found in the tropical and subtropical regions, might improve the uncertainty in the anthropogenic aerosol forcing.

It has been shown that with the prognostic scheme the treatment of precipitation is more physical, but the feedbacks are very variable. Especially the representation of the ice phase within the prognostic scheme needs to be addressed in future work, as dependencies on the treatment of collection processes and sedimentation cannot be excluded. Furthermore, the influence of recent improvements in the formation of cirrus clouds (Kuebbeler et al., 2014) or the sensitivity to ice properties (Eidhammer et al., 2014) and the number of ice water classes (Morrison and Grabowski, 2008) to the prognostic treatment of precipitation will need to be studied. To conclude, with the introduction of prognostic precipitation future steps will imply a coupling of precipitation to the radiative transfer calculations in order to ensure consistency there. In this regard, including the precipitating hydrometeors into the radiation calculation, especially for snow, should improve model fidelity and reduce compensating errors as $\mathrm{Li}$ et al. (2014) showed. 


\section{Appendix A: Approximated collection processes}

Following the formulation by Sant et al. (2013) the collection processes are derived from the stochastic collection equation for truncated moments:

$$
\begin{aligned}
& \frac{\partial M_{i}^{n}}{\partial t}=\frac{1}{2}\left[\int_{l}^{u} \int_{0}^{u-y}(x+y)^{n} f(x) f(y) K(x, y) \mathrm{d} x \mathrm{~d} y\right. \\
& \left.+\int_{0}^{l} \int_{l-y}^{u-y}(x+y)^{n} f(x) f(y) K(x, y) \mathrm{d} x \mathrm{~d} y\right] \\
& -\int_{0}^{\infty} \int_{l}^{u} x^{n} f(x) f(y) K(x, y) \mathrm{d} x \mathrm{~d} y,
\end{aligned}
$$

where $x$ and $y$ are the drop masses collecting each other, $l$ and $u$ are the lower and upper integration limits of class $i(i \in$ $\{\mathrm{c}, \mathrm{d}, \mathrm{r}\}$ ), respectively, $K(x, y)$ is the collection kernel (Sant et al., 2013, Eq. 9) and $f$ is assumed to be a four parameter modified gamma distribution:

$$
f_{i}(x)=A_{i} x^{\widetilde{v}_{i}} \exp \left(-\lambda_{i} x^{\widetilde{\mu}_{i}}\right) .
$$

To avoid solving certain integrals numerically and save computational costs the following generalized integrals,

$$
\begin{aligned}
& I_{\mathrm{cc}}^{n}=\frac{k_{\mathrm{cc}}}{2} \int_{0}^{x_{1}} \int_{x_{1}-y}^{x_{1}} f_{\mathrm{c}}(x) f_{\mathrm{c}}(y)\left(x^{2}+y^{2}\right)(x+y)^{n} \mathrm{~d} x \mathrm{~d} y, \\
& I_{\mathrm{dd}}^{n}=\frac{k_{\mathrm{dd}}}{2} \int_{x_{1}}^{x_{2}-x_{1}} \int_{x_{2}-y}^{x_{2}} f_{\mathrm{d}}(x) f_{\mathrm{d}}(y)(x+y)^{n+1} \mathrm{~d} x \mathrm{~d} y, \\
& I_{\mathrm{cd}}^{n}=k_{\mathrm{cd}} \int_{x_{2}-x_{1}}^{x_{2}} \int_{0}^{x_{2}-y} f_{\mathrm{c}}(x) f_{\mathrm{d}}(y)(x+y)^{n+1} \mathrm{~d} x \mathrm{~d} y,
\end{aligned}
$$

are approximated for the moments of number and mass density, i.e., $n \in\{0,1\}$, using a four parameter polynomial of the form:

$$
P_{4}(r)=a_{1}\left(a_{0}+r\right)^{2}+a_{2}\left(a_{0}+r\right)^{3}+a_{3}\left(a_{0}+r\right)^{4},
$$

where $r$ is the radius in $\mu \mathrm{m}$ and $a_{m}, m \in\{0,1,2,3\}$ are the fitting parameters. To this end, from simulations of Sant et al. (2013) with the 1-D kinematic cloud model, the normalized integral values are rescaled and approximated by $P_{4}(r)$ in $\log$-space with a nonlinear least square fit using a LevenbergMarquardt algorithm (Press et al., 1992), such that

$$
\left.P_{4}(r)\right|_{j k} ^{n}=\log \left(\frac{C_{j k}^{n} I_{j k}^{n}}{N_{j} N_{k}}\right)=\log \left(\mathfrak{I}_{j k}^{n}\right)
$$

for $n \in\{0,1\}$ and $j, k \in\{\mathrm{c}, \mathrm{d}\}$. The solutions are plotted in Fig. A1 and the parameters are summarized in Tables A1 and A2. Note that $\mathfrak{I}_{\mathrm{dd}}^{n}$ and $\mathfrak{I}_{\mathrm{cd}}^{n}$ are piecewise approximated for $r_{\mathrm{d}}<40 \mu \mathrm{m}$ and $r_{\mathrm{d}}>40 \mu \mathrm{m}$, because of the functional dependency of the shape parameter $\widetilde{v}_{\mathrm{d}}$ (cf. Sant et al., 2013, Eq. 12).

The integrals $I_{\mathrm{cc}}^{n}$ and $I_{\mathrm{dd}}^{n}$ (cf. Fig. A1a, b, d and e) collapse nicely onto a line due to the normalization by the number density and therefore allow for a very good fit. As pointed out before, $I_{0, c d}$ and $I_{1, \mathrm{~cd}}$ still exhibit a slight dependency on the shape parameters and the continuity condition applied to the classes (cf. Sant et al., 2013), which results in the broader range of values between 40 and $60 \mu \mathrm{m}$ in Fig. A1c and $\mathrm{f} \mathrm{de-}$ picted by the gray area. Although small, the approximations will not capture this variability. However, since the effect on produced surface precipitation is negligible (on the order of a few percent) they are a reliable alternative to the CPU intensive numerical solution of the integrals. 
Table A1. The coefficients and scaling used in the four parameter polynomials (cf. Eq. A6) for approximating the zeroth moment, i.e., $n=0$, of the integrals in Eqs. (A3)-(A5).

\begin{tabular}{lrrrrr}
\hline Coeff. & $\left.P_{4}(r)\right|_{\mathrm{cc}} ^{0}$ & $\begin{array}{c}\left.P_{4}(r)\right|_{\mathrm{dd}} ^{0} \\
r_{\mathrm{d}}<40 \mu \mathrm{m}\end{array}$ & $r_{\mathrm{d}} \geq 40 \mu \mathrm{m}$ & $r_{\mathrm{d}}<40 \mu \mathrm{m}$ & $r_{\mathrm{d}} \geq 40 \mu \mathrm{m}$ \\
\hline$a_{0}$ & -22.337 & -50.158 & -93.164 & -49.556 & -99.931 \\
$a_{1}$ & $-1.6652 \times 10^{-1}$ & $-1.8943 \times 10^{-1}$ & $-5.3859 \times 10^{-3}$ & $-1.8262 \times 10^{-1}$ & $-5.6868 \times 10^{-3}$ \\
$a_{2}$ & $-2.5767 \times 10^{-2}$ & $-1.6953 \times 10^{-2}$ & $-1.2739 \times 10^{-4}$ & $-1.6436 \times 10^{-2}$ & $-1.3552 \times 10^{-4}$ \\
$a_{3}$ & $-2.2943 \times 10^{-3}$ & $-5.1756 \times 10^{-4}$ & $-1.4120 \times 10^{-6}$ & $-5.0922 \times 10^{-4}$ & $-1.1954 \times 10^{-6}$ \\
$C_{j k}^{0}$ & $10^{-5}$ & \multicolumn{2}{c}{$10^{-2}$} & \multicolumn{2}{c}{$10^{-3}$} \\
\hline \multicolumn{7}{c}{} \\
\hline
\end{tabular}

Table A2. The coefficients and scaling used in the four parameter polynomials (cf. Eq. A6) for approximating the first moment, i.e., $n=1$, of the integrals in Eqs. (A3)-(A5).

\begin{tabular}{lrrrrr}
\hline Coeff. & $\left.P_{4}(r)\right|_{\mathrm{cc}} ^{1}$ & $\begin{array}{c}\left.P_{4}(r)\right|_{\mathrm{dd}} ^{1} \\
r_{\mathrm{d}}<40 \mu \mathrm{m}\end{array}$ & $r_{\mathrm{d}} \geq 40 \mu \mathrm{m}$ & $\left.r_{\mathrm{d}}(r)\right|_{\mathrm{cd}} ^{1}$ & $r_{\mathrm{d}} \geq 40 \mu \mathrm{m}$ \\
\hline$a_{0}$ & -22.557 & -50.376 & -101.199 & -50.121 & -109.893 \\
$a_{1}$ & $-1.7426 \times 10^{-1}$ & $-2.0805 \times 10^{-1}$ & $-4.3356 \times 10^{-3}$ & $-1.9190 \times 10^{-1}$ & $-4.8496 \times 10^{-3}$ \\
$a_{2}$ & $-2.6650 \times 10^{-2}$ & $-1.8605 \times 10^{-2}$ & $-8.9089 \times 10^{-5}$ & $-1.6820 \times 10^{-2}$ & $-9.9346 \times 10^{-5}$ \\
$a_{3}$ & $-2.240 \times 10^{-3}$ & $-5.5578 \times 10^{-4}$ & $-8.7550 \times 10^{-7}$ & $-4.9774 \times 10^{-4}$ & $-7.4402 \times 10^{-7}$ \\
$C_{j k}^{1}$ & $10^{-12}$ & \multicolumn{2}{c}{$10^{-7}$} & \multicolumn{2}{c}{$10^{-8}$} \\
\hline
\end{tabular}
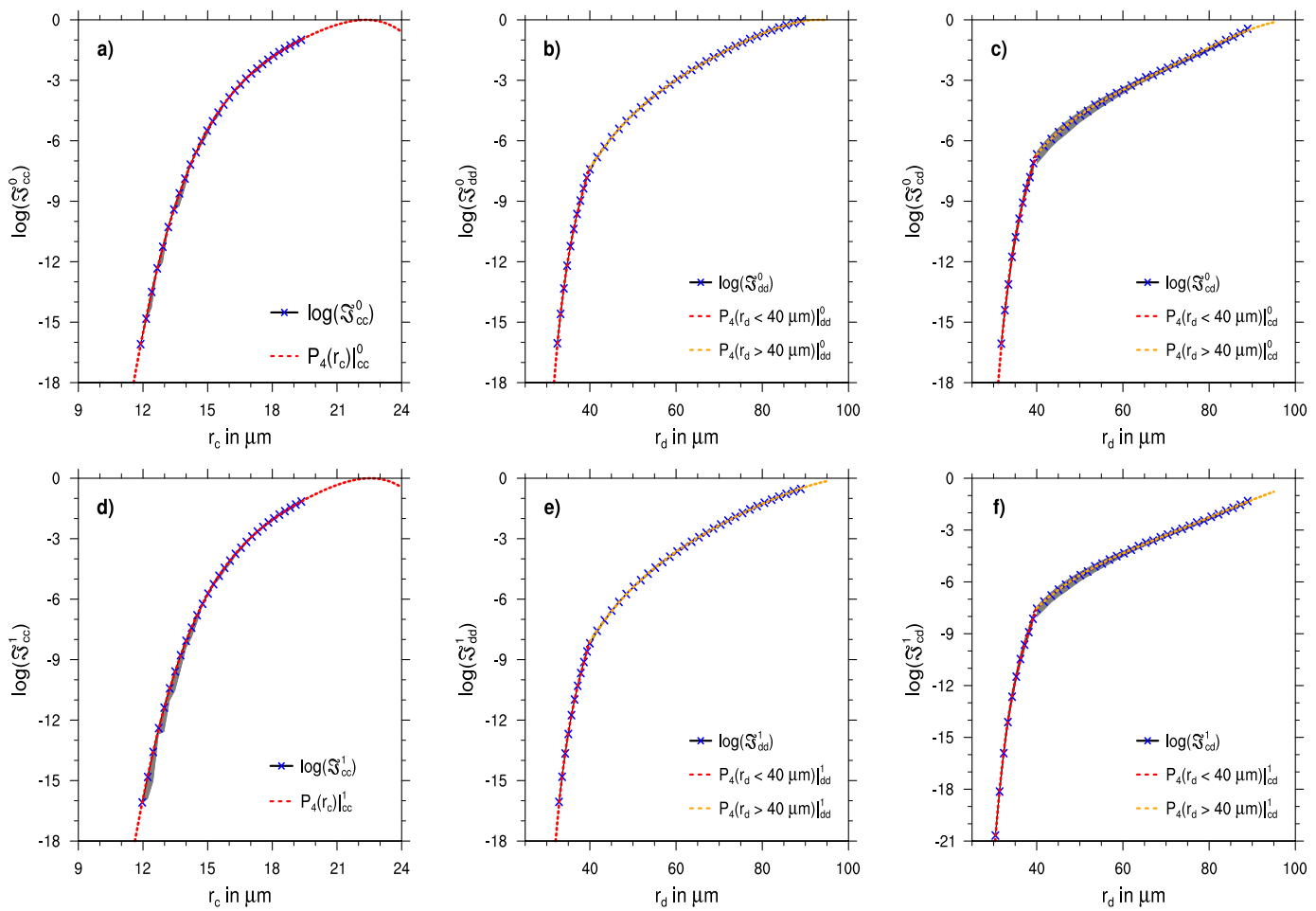

Figure A1. Approximation of Eqs. (A3)-(A5) using a four parameter polynomial $P_{4}(r)$ (cf. Eq. A7) from an ensemble of simulations with the 1-D kinematic cloud model (Sant et al., 2013). The gray area in the figures represents the range of the minimum and maximum values. Note that the gray area in (a, b) and (e) are very small and hardly recognizable. 
Acknowledgements. We would like to thank Axel Seifert for valuable comments on the manuscript, Thorsten Mauritsen, Colombe Siegenthaler-Le Drian, Francesco Isotta and Sylvaine Ferrachat for fruitful discussions and technical help. We thank Jui-Lin Li for providing the CIWC and CIWP data of Li et al. (2012). Furthermore, we also thank the three anonymous reviewers for their helpful and constructive comments that helped to improve the manuscript. This work was finished during a BMBF funded project (FKZ: 01LK1206A) at the Max Planck Institute for Meteorology in Hamburg.

Edited by: X. Liu

\section{References}

Ackerman, A., Kirkpatrick, M., Stevens, D., and Toon, O.: The impact of humidity above stratiform clouds on indirect aerosol climate forcing, Nature, 432, 1014-1017, 2004.

Adler, R. F., Huffman, G. J., Chang, A., Ferraro, R., Xie, P. P., Janowiak, J., Rudolf, B., Schneider, U., Curtis, S., Bolvin, D., Gruber, A., Susskind, J., Arkin, P., and Nelkin, E.: The version-2 Global Precipitation Climatology Project (GPCP) monthly precipitation analysis (1979-present), J. Hydrometeorol., 4, 11471167, 2003.

Albrecht, B. A.: Aerosols, cloud microphysics, and fractional cloudiness, Science, 245, 1227-1230, 1989.

Barthazy, E. and Schefold, R.: Fall velocity of snowflakes of different riming degree and crystal types, Atmos. Res., 82, 391-398, 2006.

Bellouin, N., Quaas, J., Morcrette, J.-J., and Boucher, O.: Estimates of aerosol radiative forcing from the MACC re-analysis, Atmos. Chem. Phys., 13, 2045-2062, doi:10.5194/acp-13-20452013, 2013.

Bony, S. and Dufresne, J.: Marine boundary layer clouds at the heart of tropical cloud feedback uncertainties in climate models, Geophys. Res. Lett., 32, L20806, doi:10.1029/2005GL023851, 2005.

Boucher, O., Randall, D., Artaxo, P., Bretherton, C., Feingold, G., Forster, P., Kerminen, V.-M., Kondo, Y., Liao, H., Lohmann, U., Rasch, P., Satheesh, S., Sherwood, S., Stevens, B., and Zhang, X.: Clouds and aerosols, in: Climate Change 2013: The Physical Science Basis. Contribution of Working Group I to the Fifth Assessment Report of the Intergovernmental Panel on Climate Change, edited by: Stocker, T., Qin, D., Plattner, G.-K., Tignor, M., Allen, S., Boschung, J., Nauels, A., Xia, Y., Bex, V., and Midgley, P., chap. 7, Cambridge University Press, Cambridge, United Kingdom and New York, NY, USA, 571-657, 2013.

Cziczo, D. J., Froyd, K. D., Hoose, C., Jensen, E. J., Diao, M., Zondlo, M. A., Smith, J. B., Twohy, C. H., and Murphy, D. M.: Clarifying the dominant sources and mechanisms of cirrus cloud formation, Science, 340, 1320-1324, 2013.

Dee, D. P., Uppala, S. M., Simmons, A. J., Berrisford, P., Poli, P., Kobayashi, S., Andrae, U., Balmaseda, M. A., Balsamo, G., Bauer, P., Bechtold, P., Beljaars, A. C. M., van de Berg, L., Bidlot, J., Bormann, N., Delsol, C., Dragani, R., Fuentes, M., Geer, A. J., Haimberger, L., Healy, S. B., Hersbach, H., Hólm, E. V., Isaksen, L., Kållberg, P., Köhler, M., Matricardi, M., McNally, A. P., Monge-Sanz, B. M., Morcrette, J.-J., Park, B.-K., Peubey, C., de Rosnay, P., Tavolato, C., Thépaut, J.-N., and Vitart, F.: The
ERA-interim reanalysis: configuration and performance of the data assimilation system, Q. J. Roy. Meteor. Soc., 137, 553-597, 2011.

Dentener, F., Kinne, S., Bond, T., Boucher, O., Cofala, J., Generoso, S., Ginoux, P., Gong, S., Hoelzemann, J. J., Ito, A., Marelli, L., Penner, J. E., Putaud, J.-P., Textor, C., Schulz, M., van der Werf, G. R., and Wilson, J.: Emissions of primary aerosol and precursor gases in the years 2000 and 1750 prescribed data-sets for AeroCom, Atmos. Chem. Phys., 6, 43214344, doi:10.5194/acp-6-4321-2006, 2006.

Eidhammer, T., Morrison, H., Bansemer, A., Gettelman, A., and Heymsfield, A. J.: Comparison of ice cloud properties simulated by the Community Atmosphere Model (CAM5) with in-situ observations, Atmos. Chem. Phys., 14, 10103-10118, doi:10.5194/acp-14-10103-2014, 2014.

Gettelman, A. and Morrison, H.: Advanced Two-Moment Bulk Microphysics for Global Models, Part I: Off-Line Tests and Comparison with Other Schemes, J. Climate, 28, 1268-1287, doi:10.1175/JCLI-D-14-00102.1, 2015.

Gettelman, A., Morrison, H., Terai, C. R., and Wood, R.: Microphysical process rates and global aerosol-cloud interactions, Atmos. Chem. Phys., 13, 9855-9867, doi:10.5194/acp-13-98552013, 2013.

Gettelman, A., Morrison, H., Santos, S., Bogenschutz, P., and Caldwell, P. M.: Advanced Two-Moment Bulk Microphysics for Global Models, Part II: Global Model Solutions and Aerosol-Cloud Interactions, J. Climate, 28, 1288-1307, doi:10.1175/JCLI-D-14-00103.1, 2015.

Greenwald, T. J., Stephens, G. L., Vonderhaar, T. H., and Jackson, D. L.: A physical retrieval of cloud liquid water over the global oceans using Special Sensor Microwave Imager (SSM/I) observations, J. Geophys. Res., 98, 18471-18488, 1993.

Ghan, S. J. and Easter, R. C.: Computationally efficient approximations to stratiform cloud microphysics parameterization, Mon Weather Rev., 120, 1572-1582, 1992.

Hahn, C. J., Warren, S. G., and London, J.: Climatological data for clouds over the globe from surface observations, 1982-1991: the total cloud edition, Tech. rep., ORNL/CDIAC-72 NDP-026A Oak Ridge National Laboratory, Oak Ridge Tennessee, USA, 47 pp., 1994.

Han, Q., Rossow, W. B., Chou, J., and Welch, R. M.: Global survey of the relationships of cloud albedo and liquid water path with droplet size using ISCCP, J. Climate, 11, 1516-1528, 1998.

Jiang, H., Xue, H., Teller, A., Feingold, G., and Levin, Z.: Aerosol effects on the lifetime of shallow cumulus, Geophys. Res. Lett., 33, L14806, doi:10.1029/2006GL026024, 2006.

Kärcher, B. and Ström, J.: The roles of dynamical variability and aerosols in cirrus cloud formation, Atmos. Chem. Phys., 3, 823838, doi:10.5194/acp-3-823-2003, 2003.

Khairoutdinov, M. and Kogan, Y.: A new cloud physics parameterization in a large-eddy simulation model of marine stratocumulus, Mon. Weather Rev., 128, 229-243, 2000.

Kuebbeler, M., Lohmann, U., Hendricks, J., and Kärcher, B.: Dust ice nuclei effects on cirrus clouds, Atmos. Chem. Phys., 14, 3027-3046, doi:10.5194/acp-14-3027-2014, 2014.

Levkov, L., Rockel, B., Kapitza, H., and Raschke, E.: 3D mesoscale numerical studies of cirrus and stratus clouds by their time and space evolution, Beitr. Phys. Atmosph., 65, 35-58, 1992. 
Li, J.-L. F., Waliser, D. E., Chen, W.-T., Guan, B., Kubar, T., Stephens, G., Ma, H.-Y., Deng, M., Donner, L., Seman, C. and Horowitz, L.: An observationally based evaluation of cloud ice water in CMIP3 and CMIP5 GCMs and contemporary reanalyses using contemporary satellite data, J. Geophys. Res., 117, D16105, doi:10.1029/2012JD017640, 2012.

Li, J.-L. F., Forbes, R. M., Waliser, D. E., Stephens, G., and Lee, S.: Characterizing the radiative impacts of precipitating snow in the ECMWF Integrated Forecast System global model, J. Geophys. Res. Atmos., 119, 9626-9637, doi:10.1002/2014JD021450, 2014.

Lin, H. and Leaitch, R.: Development of an in-cloud aerosol activation parameterization for climate modelling, in: WMO Workshop on Measurements of Cloud Properties for Forecasts of Weather and Climate, Mexico City, 23-27 June 1997, 328-335, 1997.

Loeb, N. G., Wielicki, B. A., Doelling, D. R., Smith, G. L., Keyes, D. F., Kato, S., Manalo-Smith, N., and Wong, T.: Toward optimal closure of the Earth's top-of-atmosphere radiation budget, J. Climate, 22, 748-766, 2009.

Lohmann, U. and Ferrachat, S.: Impact of parametric uncertainties on the present-day climate and on the anthropogenic aerosol effect, Atmos. Chem. Phys., 10, 11373-11383, doi:10.5194/acp10-11373-2010, 2010.

Lohmann, U. and Hoose, C.: Sensitivity studies of different aerosol indirect effects in mixed-phase clouds, Atmos. Chem. Phys., 9, 8917-8934, doi:10.5194/acp-9-8917-2009, 2009.

Lohmann, U. and Roeckner, E.: Design and performance of a new cloud microphysics scheme developed for the ECHAM general circulation model, Clim. Dynam., 12, 557-572, 1996.

Lohmann, U., Stier, P., Hoose, C., Ferrachat, S., Kloster, S., Roeckner, E., and Zhang, J.: Cloud microphysics and aerosol indirect effects in the global climate model ECHAM5-HAM, Atmos. Chem. Phys., 7, 3425-3446, doi:10.5194/acp-7-3425-2007, 2007.

Lohmann, U., Spichtinger, P., Jess, S., Peter, T., and Smit, H.: Cirrus cloud formation and ice supersaturated regions in a global climate model, Environ. Res. Lett., 3, 045022, doi:10.1088/17489326/3/4/045022, 2008.

Lohmann, U., Rotstayn, L., Storelvmo, T., Jones, A., Menon, S., Quaas, J., Ekman, A. M. L., Koch, D., and Ruedy, R.: Total aerosol effect: radiative forcing or radiative flux perturbation?, Atmos. Chem. Phys., 10, 3235-3246, doi:10.5194/acp-10-32352010, 2010.

Lüpkes, C., Beheng, K., and Doms, G.: A Parameterization Scheme for Simulating Collision/Coalescence of Water Drops, Beitr. Phys. Atmosph., 62, 289-306, 1989.

Mauritsen, T., Stevens, B., Roeckner, E., Crueger, T., Esch, M., Giorgetta, M., Haak, H., Jungclaus, J., Klocke, D., Matei, D., Mikolajewicz, U., Notz, D., Pincus, R., Schmidt, H., and Tomassini, L.: Tuning the climate of a global model, J. Adv. Model. Earth Syst., 4, M00A01, doi:10.1029/2012MS000154, 2012.

Morrison, H. and Grabowski, W. W.: A Novel Approach for Representing Ice Microphysics in Models: Description and Tests Using a Kinematic Framework, J. Atmos. Sci., 65, 1528-1548, 2008.

Morrison, H. and Milbrandt, J. A.: Parameterization of Cloud Microphysics Based on the Prediction of Bulk Ice Particle Properties. Part I: Scheme Description and Idealized Tests, J. Atmos. Sci., 72, 287-311, 2015.
Morrison, H., Milbrandt, J. A., Bryan, G. H., Ikeda, K., Tessendorf, S. A., and Thompson, G.: arameterization of Cloud Microphysics Based on the Prediction of Bulk Ice Particle Properties, Part II: Case Study Comparisons with Observations and Other Schemes, J. Atmos. Sci., 72, 312-339, 2015.

Müller, M.: Sedimentation of hydrometeors in ECHAM, Master's thesis, ETH Zurich, Zurich, 63 pp., 2007.

Murphy, D., Solomon, S., Portmann, R., Rosenlof, K., Forster, P., and Wong, T.: An observationally based energy balance for the Earth since 1950, J. Geophys. Res., 114, D17107, doi:10.1029/2009JD012105, 2009.

Posselt, R. and Lohmann, U.: Introduction of prognostic rain in ECHAM5: design and single column model simulations, Atmos. Chem. Phys., 8, 2949-2963, doi:10.5194/acp-8-2949-2008, 2008a.

Posselt, R. and Lohmann, U.: Influence of Giant CCN on warm rain processes in the ECHAM5 GCM, Atmos. Chem. Phys., 8, 37693788, doi:10.5194/acp-8-3769-2008, 2008b.

Posselt, R. and Lohmann, U.: Sensitivity of the total anthropogenic aerosol effect to the treatment of rain in a global climate model, Geophys. Res. Lett., 36, L02805, doi:10.1029/2008GL035796, 2009.

Press, W. H., Teukolsky, S. A., Vetterling, W. T., and Flannery, B. P.: Numerical Recipes in FORTRAN 77: The Art of Scientific Computing. 2nd ed. Fortran Numerical Recipes, Vol. 1, Cambridge University Press, Cambridge, New York, NY, USA, 933 pp., 1992.

Quaas, J., Ming, Y., Menon, S., Takemura, T., Wang, M., Penner, J. E., Gettelman, A., Lohmann, U., Bellouin, N., Boucher, O., Sayer, A. M., Thomas, G. E., McComiskey, A., Feingold, G., Hoose, C., Kristjánsson, J. E., Liu, X., Balkanski, Y., Donner, L. J., Ginoux, P. A., Stier, P., Grandey, B., Feichter, J., Sednev, I., Bauer, S. E., Koch, D., Grainger, R. G., Kirkevåg, A., Iversen, T., Seland, Ø., Easter, R., Ghan, S. J., Rasch, P. J., Morrison, H., Lamarque, J.-F., Iacono, M. J., Kinne, S., and Schulz, M.: Aerosol indirect effects - general circulation model intercomparison and evaluation with satellite data, Atmos. Chem. Phys., 9, 8697-8717, doi:10.5194/acp-98697-2009, 2009.

Reitter, S., Fröhlich, K., Seifert, A., Crewell, S., and Mech, M.: Evaluation of ice and snow content in the global numerical weather prediction model GME with CloudSat, Geosci. Model Dev., 4, 579-589, doi:10.5194/gmd-4-579-2011, 2011.

Roeckner, E., Bäuml, G., Bonaventura, L., Brokopf, R., Esch, M., Giorgetta, M., Hagemann, S., Kirchner, I., Kornblueh, L., Manzini, E., Rhodin, A., Schlese, U., Schulzweida, U., and Tompkins, A.: The atmospheric general circulation modell ECHAM5, Part I: Model description, Tech. Rep. 349, MaxPlanck-Institute for Meteorology, Hamburg, Germany, 140 pp., 2003.

Rogers, R., Ethier, S., Baumgardner, D., Carter, D., and Ecklund, W.: Comparison of raindrop size distributions measured by radar wind profiler and by airplane, J. Appl. Meteorol., 32, 694699, 1993.

Rosenfeld, D., Wang, H., and Rasch, P. J.: The roles of cloud drop effective radius and LWP in determining rain properties in marine stratocumulus, Geophys. Res. Lett., 39, L13801, doi:10.1029/2012GL052028, 2012. 
Rossow, W. B. and Schiffer, R. A.: Advances in understanding clouds from ISCCP, B. Am. Meteorol. Soc., 80, 2261-2287, 1999.

Saleeby, S. M. and Cotton, W. R.: A large-droplet mode and prognostic number concentration of cloud droplets in the Colorado State University Regional Atmospheric Modeling System (RAMS), Part I: Module descriptions and supercell test simulations, J. Appl. Meteor., 43, 182-195, 2004.

Sant, V.: A new two moment collision-coalescence parameterization for simulating drizzling stratiform clouds. Ph.D. dissertation, ETH Zurich, 177 pp., 2012.

Sant, V., Lohmann, U., and Seifert, A.: Performance of a triclass parameterization for the collision-coalescence process in shallow clouds, J. Atmos. Sci., 70, 1744-1767, 2013.

Scott, N. A., Chédin, A., Armante, R., Francis, J., Stubenrauch, C., Chaboureau, J.-P., Chevallier, F., Claud, C., and Cheruy, F.: Characteristics of the TOVS pathfinder path-B dataset, B. Am. Meteorol. Soc., 80, 2679-2701, 1999.

Seifert, A.: On the parameterization of evaporation of raindrops as simulated by a one-dimensional rainshaft model, J. Atmos. Sci., 65, 3608-3619, 2008.

Spichtinger, P. and Gierens, K. M.: Modelling of cirrus clouds Part 1a: Model description and validation, Atmos. Chem. Phys., 9, 685-706, doi:10.5194/acp-9-685-2009, 2009.

Srivastava, R. C.: Parameterization of raindrop size distributions, J. Atmos. Sci., 35, 108-117, 1978.

Stephens, G.: Cloud feedbacks in the climate system: a critical review, J. Climate, 18, 237-273, 2005.

Stevens, B. and Bony, S.: What are climate models missing?, Science, 340, 1053-1054, 2013.

Stevens, B. and Feingold, G.: Untangling aerosol effects on clouds and precipitation in a buffered system, Nature, 461, 607-613, 2009.

Stier, P., Feichter, J., Kinne, S., Kloster, S., Vignati, E., Wilson, J., Ganzeveld, L., Tegen, I., Werner, M., Balkanski, Y., Schulz, M., Boucher, O., Minikin, A., and Petzold, A.: The aerosol-climate model ECHAM5-HAM, Atmos. Chem. Phys., 5, 1125-1156, doi:10.5194/acp-5-1125-2005, 2005.

Sundqvist, H., Berge, E., and Kristjansson, J. E.: Condensation and cloud parameterization studies with a mesoscale numerical weather prediction model, Mon. Weather Rev., 117, 1641-1657, 1989.

Twomey, S.: Pollution and planetary albedo, Atmos. Environ., 8, 1251-1256, 1974.

van Zanten, M. C., Stevens, B., Vali, G., and Lenschow, D. H.: Observations of drizzle in nocturnal marine stratocumulus, J. Atmos. Sci., 62, 88-106, 2005.
Von der Haar, T. H., Bytheway, J. L., and Forsythe, J. M.: Weather and climate analyses using improved global water vapor observations, Geophys. Res. Lett., 39, L15802, doi:10.1029/2012GL052094, 2012.

Waliser, D. E., Li, J.-L. F., Woods, C. P., Austin, R. T., Bacmeister, J., Chern, J., Del Genio, A., Jiang, J. H., Kuang, Z., Meng, H., Minnis, P., Platnick, S., Rossow, W. B., Stephens, G. L., SunMack, S., Tao, W.-K., Tompkins, A. M., Vane, D. G., Walker, C., and $\mathrm{Wu}, \mathrm{D}$.: Cloud ice: a climate model challenge with signs and expectations of progress, J. Geophys. Res., 114, D00A21, doi:10.1029/2008JD010015, 2009.

Walters, D. N., Williams, K. D., Boutle, I. A., Bushell, A. C., Edwards, J. M., Field, P. R., Lock, A. P., Morcrette, C. J., Stratton, R. A., Wilkinson, J. M., Willett, M. R., Bellouin, N., Bodas-Salcedo, A., Brooks, M. E., Copsey, D., Earnshaw, P. D., Hardiman, S. C., Harris, C. M., Levine, R. C., MacLachlan, C., Manners, J. C., Martin, G. M., Milton, S. F., Palmer, M. D., Roberts, M. J., Rodríguez, J. M., Tennant, W. J., and Vidale, P. L.: The Met Office Unified Model Global Atmosphere 4.0 and JULES Global Land 4.0 configurations, Geosci. Model Dev., 7, 361-386, doi:10.5194/gmd-7-361-2014, 2014.

Wang, M., Ghan, S., Ovchinnikov, M., Liu, X., Easter, R., Kassianov, E., Qian, Y., and Morrison, H.: Aerosol indirect effects in a multi-scale aerosol-climate model PNNL-MMF, Atmos. Chem. Phys., 11, 5431-5455, doi:10.5194/acp-11-5431-2011, 2011.

Weng, F. and Grody, N.: Retrieval of cloud liquid water using the Special Sensor Microwave Imager (SSM/I), J. Geophys. Res., 99, 25535-25551, 1994.

Wentz, F.: A well-calibrated ocean algorithm for SSM/I, J. Geophys. Res., 102, 8703-8718, 1997.

Wielicki, B. A., Barkstrom, B. R., Harrison, E. F., Lee III, R. B., Louis Smith, G., and Cooper, J. E.: Clouds and the Earth's Radiant Energy System (CERES): an earth observing system experiment, B. Am. Meteorol. Soc., 77, 853-868, 1996.

Wild, M., Folini, D., Schär, C., Loeb, N., Dutton, E. G., and KönigLanglo, G.: The global energy balance from a surface perspective, Clim. Dynam., 40, 3107-3134, 2013.

Wood, R.: Parametrization of the effect of drizzle upon the droplet effective radius in stratocumulus clouds, Q. J. Roy. Meteor. Soc., 126, 3309-3324, 2000.

Wylie, D., Jackson, D. L., Menzel, W. P., and Bates, J. J.: Trends in global cloud cover in two decades of HIRS observations, J. Climate, 18, 3021-3031, 2005. 